\begin{tabular}{l|lr}
$\begin{array}{l}\text { Università } \\
\text { della } \\
\text { Svizzera } \\
\text { italiana }\end{array}$ & $\begin{array}{l}\text { Faculty } \\
\text { of Economics }\end{array}$ & IdEP Economic Papers \\
& & \\
\hline & & $2020 / 01$
\end{tabular}

P. Bello

The environmental cost and the accident externality of driving: evidence from the Swiss franc's appreciation 


\title{
The environmental cost and the accident externality of driving: Evidence from the Swiss franc's appreciation. *
}

\author{
Bello, Piera
}

April 22, 2020

\begin{abstract}
This study investigates the effects of driving on air quality and road safety by exploiting exogenous variation in traffic flows associated with the Swiss franc's appreciation. During the Swiss franc's appreciation, the volume of cars crossing the Swiss-Italian border rose considerably - the higher purchasing power of Swiss francs in the Euro area induced more Italian workers to cross the border daily to work in Switzerland and increased the propensity for Swiss consumers to shop abroad (Bello, 2019). By using hourly data on traffic flows, road accidents, and air pollution, I show that the higher mobility across the border increased the concentration of oxides of nitrogen at peak hours during working days and the risk of road traffic accidents with (mild) personal injuries at late morning on non-working days. The elasticity to the the number of cars of both variables of interest turns out to be larger than 1, providing evidence of a harmful externality. This suggests the need for programmes that treat traffic congestion, air quality, and road safety jointly. Moreover, the existence of an externality has important implications for optimal road use pricing.

Keywords: safety and accidents, air pollution, traffic, geographic labor mobility, crossborder shopping, exchange rate JEL classification codes: Q53, R41, J61, D12

\footnotetext{
* Piera Bello, Università della Svizzera italiana, Via Buffi 13, 6942 Lugano, Switzerland, piera.bello@usi.ch;
} Present address: Department of Economics, University College London. I am very grateful to Vincenzo Galasso and Mario Padula for their guidance and support. I thank Marco Steiger "Ufficio del monitoraggio ambientale, Canton Ticino" for providing data on air pollution and traffic flows. I benefited from the very useful suggestions from participants at 9th Ifo Dresden Workshop on Regional Economics, at the 2019 SIEP Annual Congress, and at the 2017 RES Annual Conference. Financial support from the Swiss National Science Foundation (grant Early Postdoc.Mobility -171885) is gratefully acknowledged. Usual disclaimers apply.
\end{abstract}




\section{Introduction}

The rapid growth of urban areas coupled with an increasing demand for urban transport services explains a major portion of the increasing trend in traffic jams observed in the last century. But the use of roads comes at a cost. Falling average speed of vehicle decreases the efficiency of fuel consumption and increases the amount of air pollution emission per vehicle mile of travel. Air quality in many large urban areas is deteriorating and outdoor air pollution has become one of the main environmental health problems of developing and developed countries. However, congestion can be beneficial for road safety. Some empirical evidence suggests a negative relationship between fatalities and traffic density. The hypothesis is that, when the number of cars on roads increases, at a low level of traffic density, the number of fatalities also increases, while in the presence of congestion, it decreases or increases at a lower rate. This points out the importance of thoroughly investigating the functional relationship between traffic congestion, traffic fatalities and urban air quality in order to implement policies which treat these different aspects jointly.

So far, most of the relevant literature has focused, separately, on either the relationship between car accident probability and traffic flows, or on that between the latter and air pollution. For instance, Dickerson, Peirson, and Vickerman (2000) and Edlin and Karaca-Mandic (2006) investigated the existence of an accident externality of driving. An accident externality is defined as the difference between the marginal and average accident rates and occurs when an extra vehicle leads to an additional risk of an accident for all vehicles while it faces only the average risk. In other words, when a one percent increase in aggregate driving increases aggregate accident costs by more than one percent. Dickerson, Peirson, and Vickerman (2000) by using data from London and analysing the accidents-flow relationship across several type of roads and geographical areas found that, while there is a near-proportional relationship at low traffic flows, a driving externality is present in high traffic volume areas. Edlin and Karaca-Mandic (2006) provided similar evidence using data on insurance premiums in California. However, most of these studies, by not addressing the omitted variables problem (for instance, road characteristics and time varying factors may affect both traffic flows and accident probability), fail to provide evidence of a causal relationship. An exception is represented by Romem and Shurtz (2016), who estimated the effect of traffic volume on the probability of accident by exploiting exogenous variation in traffic flows stemming from religious observance of the Jewish Sabbath in Israel. They provided evidence of a non-linear relationship between traffic and accidents existing mainly on highly perilous roads. 
Regarding the relationship between traffic volume and air quality deprivation, most recent studies have analysed the effects of driving restrictions or transport policies on levels of air pollution. Viard and Fu (2015), for instance, investigated the effects of the Beijing odd-even policy, which restricted cars to drive only every other day, and found that it improved air quality and reduced discretionary work time.

This paper contributes to this foregoing literature by being able to identify an underlying causation between cross-border traffic and both road safety and air quality. It provides evidence of an accident and environmental externality of cross-border driving, whose size changes across time-intervals characterized by different volumes of traffic. The analysis focuses on Ticino, the southernmost canton of Switzerland, and exploits exogenous variation in traffic flows generated by the Swiss franc's appreciation.

In Ticino, a quarter of the employed workforce consists of cross-border workers commuting daily, mainly from Italy. Moreover, according to the GFK survey, more than $50 \%$ of Swiss consumers, in Ticino, regularly cross the border to buy in the cheaper Italy. The EUR/Sfr exchange rate has been found to be an important determinant of these mobility flows. Indeed, Bello (2019) found that, in 2010, in response to the Swiss franc appreciation, which resulted in a higher purchasing power of Swiss wages, more Italian workers decided to cross the border to work in Switzerland, and the propensity for Swiss consumers to shop across the border increased. The number of vehicles along the border increased, in fact, by 1.6-2.9\% during specific time intervals. The larger number of Italian people commuting to Switzerland to work translated into an increase in traffic flows at early morning (from Italy to Switzerland) and at the afternoon (from Switzerland to Italy) on working days; while the effect of the Swiss franc appreciation on cross-border shopping led to a larger number of cars along the border at late morning mainly on non-working days.

This exogenous change in the mobility across the Swiss-Italian border provides an ideal setting to analyse the causal effect that traffic flows have on the road safety and the air quality level. In pursuing this objective, I collected, for the 2005-2015 period, hourly data on the number of road accidents for each municipality in Ticino; and data on the concentration of oxides of nitrogen (NOx) and on traffic flows coming, respectively, from 25 traffic-counting stations and 13 air-monitoring stations located throughout the canton. I calculate the road distance between each municipality and the closest border post. By assuming that municipalities located closer to the border are more affected by cross-border commuting, I distinguish two groups of municipalities and perform a Difference in Differences analysis. Air monitoring stations and traffic counting stations are divided into the two groups according to which 
municipality the station belongs. Then, I proceed as follows. First, I replicate the analysis of Bello (2019) and investigate the effect that the Swiss franc appreciation had on traffic flows, for both working days and nonworking days, during five different time intervals. I estimate the elasticity of traffic flows to the exchange rate. Secondly, I turn to investigating the effects of the exchange rate on air quality and road safety and provide an estimate for the elasticity of the NOx concentration and the car accident probability to the number of cars on the road. Again, I distinguish working days from nonworking days and five time intervals. Finally, by putting these two sets of results together, I estimate the elasticity of my two variables of interests- NOx concentration and car accident probability- to the number of cars. I also run a robustness check to verify that my results are robust to implementing a 2SLS strategy, where the exchange rate is used as an instrument for traffic flows.

The findings of this paper show that the appreciation of the Swiss franc was associated with an increase in the monthly concentration of oxides of nitrogen and in the monthly car accident probability. The significance and the magnitude of the effect differ across time intervals and weekdays. At peak hours on working days, a $10 \%$ appreciation of the Swiss franc increased the level of traffic flows by 1.6-2.6\%. By reducing traffic speeds, this rise in the number of cars on the roads drastically worsen air quality - the concentration of nitrogen oxides increased by 3.1-3.4\% - but had no effect on the probability of a car accident. Conversely, on late morning, a $10 \%$ appreciation of the Swiss franc, which led to an 1.6-1.7\% increase in traffic flows mainly on non-working days, increased the risk of a car accident with mild personal injuries - the car accident probability rose by $8 \%$-but did not affect air quality. This is explained by the fact that the increase in the number of cars on the roads on late morning, on nonworking days, was not enough to reduce the speed of vehicles and, consequently, did not produce a statistically significant increase in the level of NOx concentration, which is mostly associated with congestion. Overall, the elasticity of pollution and car accident probability to the number of cars turns out to be much larger than 1 . This provides evidence of a harmful externality associated with cross-border travel: one additional car on the roads almost doubles the probability of a car accident and the concentration of NOx in the air. Similar results are obtained by implementing an IV strategy and using the CHF/ EUR exchange rate as an instrument for traffic flows at the border.

This paper also contributes to the literature that studies the effect of economic variables, such as income level and unemployment rates, on health outcomes (Tihansky, 1974; Wagenaar, 1984; Grossman and Krueger, 1991). Recent papers have reported a positive health effects of economic crises in the short-run. Ruhm (2000), by focusing on the US, showed that during 
downturns in the US, mortality decreased. Granados (2005) and Bertoli, Grembi, and Castello (2018) using Spanish data showed that the Great Recession reduced traffic accidents in Spain and changed their composition. These positive effects are mostly driven by a lower number of employed workers and a corresponding lower number of drivers. However, the effects that a recession or the employment rate of a country might have on health risk in its neighbouring countries has not yet been studied. The results of this paper provide some insight on this point.

The paper is structured as follows. Section 2 describes the identification strategy and the data. Section 3 presents the empirical strategy and the OLS results, while Section 4 reports the results of the IV strategy. Finally, Section 5 discusses the analysis and Section 6 concludes.

\section{The data and the identification strategy}

\subsection{Data}

This paper uses data on road traffic flows, road traffic accidents and air pollutant concentrations. The data regarding traffic flows and air quality are from the Sezione Mobilità del Canton Ticino. Specifically, the dataset consists of hourly information on the concentration of the most important pollutants and on the number of vehicles, from 2005 throught 2015, coming from air monitoring stations and traffic counting stations located through the canton. For the air quality analysis, I focus on data on nitrogen oxides due to the high frequency of missing values for the other pollutants. The concentration of nitrogen oxides is among the most commonly used indicators of air pollution - nitrogen oxides are formed from the burning of fossil fuels (including vehicle emissions) and are associated with adverse health effects, including respiratory problems and lung damage. ${ }^{1}$ The dataset on traffic accidents comes from the Federal Roads Office and includes all accidents reported to the police in Switzerland in the 2005-2015 period. For any accident, there is information on date, time and location (municipality).

Finally, I obtained daily data on the EUR/SFr exchange rate from the Swiss National Bank.

\subsection{Identification}

In order to investigate the effects of cross-border traffic flow on the car accident probability and the air quality level, I proceed as follows. First, I replicate the analysis provided in Bello

\footnotetext{
${ }^{1}$ Nitrogen oxides also contribute to the formation of fine particles (PM) and ground level ozone.
} 
(2019) and analyse the effect of the Swiss franc appreciation on the number of cars. Second, I investigate the effect of exchange rate movements on both the accident probability and the air concentration of nitrogen oxides (NOx). Finally, I combine the two results and estimate the effect of cross-border travel on road safety and air quality deprivation. In doing so, I am able to address the omitted variable bias that would arise from directly regressing traffic volume on car accident probability and NOx emissions. ${ }^{2}$

Specifically, the identification strategy entails distinguishing two groups of municipalities in Ticino, according to their distance from the border, and comparing the patterns of the variables of interest between the two groups during the change in the Eur/Chf exchange rate. The two groups of municipalities are so identified: municipalities within $10 \mathrm{~km}$ of the border are in the Treatment Group, while the rest of them are in the Control Group. Air monitoring stations and traffic counting stations are divided into the two groups according to which municipality the station belongs. By comparing the two groups, it is possible to disentangle the impact of the monetary shock on both the car accident probability and the air pollutant concentration due to the rise in cross-border mobility from other effects that the exchange rate might have had. Moreover, since the changes in traffic flows are due to an exougenous monetary shock, I can reasonably assume that they are uncorrelated to any other factors that influence the accident risk and the level of air pollution. This allows me to identify the causal effect of cross-border traffic flows on my variables of interests.

Figure 1 shows the location of air monitoring stations and of traffic counting stations, in the Treatment and Control Group. The Treatment Group consists of 48 municipalities, while the Control Group is composed of 88 municipalities. In the analysis on traffic flows, I exclude the stations not active over the entire period of analysis as well as traffic-counting stations located on highways in order to exclude trade-related traffic flows. My final dataset consists of an unbalanced panel of 16 air monitoring stations and 24 traffic counting station. 8 air monitoring stations and 11 traffic counting stations are allocated to the Treatment Group, the rest is included in the Control Group.

\subsection{Descriptive statistics}

Figure 2 presents the evolution of the EUR/SFr exchange rate, i.e. the value of the Euro expressed in Swiss francs, from 2000 through 2015. In the aftermath of the global financial

\footnotetext{
${ }^{2}$ The bias would derive from omitting road characteristics or time-varying variables affecting simultaneously the two variables. For instance, lower levels of traffic flows are observed at hours in which people are more tired and therefore more likely to be involved in a car accident. This would suggest, wrongly, the existence of a positive externality of driving.
} 
crisis of 2008, the Swiss franc gained appreciably. The EUR/SFr exchange rate passed, in fact, from 1,61 to 1,25. This was due to the special status of the Swiss franc as a typical safe haven currency. In an attempt to counteract the appreciation, the Swiss National Bank (SNB) on September 2011 decided to introduce a minimum exchange rate of CHF 1.2 per euro. To hold this ceiling, the SNB was forced to buy foreign currency in enormous quantities. Then in January 2015, in view of large quantitative easing packages from the European Central Bank, which would put substantial upward pressure on the Swiss Franc, the SNB announced that the minimum exchange rate for the Swiss franc against the euro would no longer be maintained and removed the cap. The Swiss franc immediately soared by $30 \%$ in value against the euro. The value of 1 euro fell to just Sfr 0.85 .

In order to provide evidence for the increase in traffic flows following the Swiss franc appreciation, in Figures 3, I show the correlation between the exchange rate and the average number of cars crossing a traffic counting station in the Treatment and Control Group. The figures show a clear increase in the average number of vehicles for the Treatment Group after the currency began to appreciate in 2008. The traffic flows seem to remain constant over time for the Control Group instead.

Finally, Tables 1, 2, and 3, provide summary statistics for my variables of interests. Table 1 shows the hourly average number of cars during 5 time intervals (5-9am; 10am-1pm; 2pm8pm; 9pm-11pm; 0am-4am), across the two groups of municipalities and for the two driving directions. For the same time-intervals and groups of municipalities, Table 2 and Table 3 report the hourly concentrations of NOx in parts per million (ppb) and the average probability that at least one car accident occurs in a given hour, respectively. I distinguish between accidents with minor personal injuries, accidents with severe personal injuries and accidents with material damages.

\section{Empirical Strategy}

My empirical strategy consists of 3 steps. In the first step, I replicate the analysis provided by Bello (2019) and estimate the effect of the appreciation of the Swiss franc on the number of cars along the border. I aggregate the daily data at the monthly level, but I preserve the hourly structure of the data and distinguish working days from non-working days (Saturday and Sunday). Then, I estimate the following model:

$$
\text { Cars }_{i h m y}=\eta_{1} \ln e_{m y}+\eta_{2} \ln e_{m y} * \text { Treat }_{i}+\eta_{3} X_{m y}+\eta_{4}{\text { After } 2007_{y}}+f_{i}+m_{m}+\epsilon_{i h m y}
$$


where Cars $_{\text {ihmy }}$ is the log of the monthly average number of cars crossing the traffic-counting station $i$ at the hour $h$, in the month $m$ and year $y$.

I estimate the equation separately for working days and non-working days (Saturday and Sunday), for each travel direction and for 5 temporal intervals, i.e. 5-9am, 10am-1pm, 1pm8pm, 9pm-11pm, and 12am-4am. Variable ln $e_{m y}$ represents the log of the EUR/SFr exchange rate, whereas Treat $_{i}$ is a dummy for traffic counting stations located within $10 \mathrm{~km}$ of the border. $\ln e_{m y} *$ Treat $_{i}$ is the interaction term between the dummy and the exchange rate and measures the effect of our interest. $X_{m y}$ is a vector of control variables: the log of the Swiss GDP, the log of the Italian GDP and the log of the unemployment rate in Lombardy. ${ }^{3}$ As in Bello (2019), I include a dummy for the period after full liberalization of the Swiss labour market to EU immigrants, i.e. after 2007 (after $2007 y) .{ }^{4}$ Finally, I include municipal fixed effects and month of the year fixed effects and indicate them with $f_{i}$ and $m_{m}$, respectively.

In the second step, I estimate the effect of the appreciation of the Swiss franc on the air pollutant concentration level and the road accident risk.

For the air pollutant concentration, I aggregate the daily data into monthly averages. Again, I preserve the hourly structure of the data and distinguish four time intervals and working days from non-working days (Saturday and Sunday). I run the following model:

$$
\text { Polihmy }_{i}=\eta_{1} \ln e_{m y}+\eta_{2} \ln e_{m y} * \text { Treat }_{i}+\eta_{3} X_{m y}+f_{i}+m_{y}+\text { after } 2007_{y}+\epsilon_{i h m y}
$$

where Pol $_{i h m y}$ is the log of the monthly concentration of NOx in municipality $i$ at the hour $h$, in the month $m$ and year $y$.

Finally, for the car accident probability, I convert the daily data to monthly totals and construct a binary variable equal to 1 if at least one accident occurs. ${ }^{5}$ The hourly structure of the data is preserved.

Then, I estimate a linear probability model:

$$
A c c_{i h m y}=\eta_{1} \ln e_{m y}+\eta_{2} \ln e_{m y} * \text { Treat }_{i}+\eta_{3} X_{t}+f_{i}+m_{m}+\text { after } 2007_{y}+\epsilon_{i h m y}
$$

this time $A c c_{i h m y}$ is a dummy variable that takes value 1 if at least one accident occurs in municipality $i$ at the hour $h$, in the month $m$ and year $y$.

\footnotetext{
${ }^{3}$ For the Swiss GDP, the Italian GDP and the unemployment rates I use quarterly data.

${ }^{4}$ In 2007, Switzerland fully opened its labor market to EU citizens. However, the liberalization was gradually implemented. With regards to cross-border workers three distinct phases can be identified: partial liberalization (1999-2004), full liberalization in border regions (2004-2007) and full liberalization anywhere in Switzerland (post-2007).

${ }^{5}$ I decided to use this approximation instead of the total number of accidents because in the monthly-hourmunicipality observations in which at least one accident is observed, almost $86 \%$ have exactly one accident.
} 


\subsection{Results on Traffic Flows}

The results regarding the effects of the exchange rate on traffic flows are presented in Table 4. Traffic flows from Italy to Switzerland are analysed in Panel 1 and those from Switzerland to Italy in Panel 2. In line with the results provided in Bello (2019), columns 1-2 of the Table 4 show that a $10 \%$ appreciation of the Swiss franc increased the number of cars crossing the Italian border by $2.7 \%$ more than in the rest of the canton in early morning, which corresponds to 16 additional cars per hour and per traffic counting station. In line with the cross-border labour supply hypothesis, I find that the interaction term is negative and statistically significant also in column 7 Panel 2, which refers to the traffic flows from Switzerland to Italy between $2 \mathrm{pm}-8 \mathrm{pm}$, when, presumably, cross border workers are returning to Italy. The estimated effect is $1.6 \%$ and corresponds to seven additional cars per hour. The interaction terms in columns 1-2 in Table 4 Panel 2 and columns 5-6 Table 4 Panel 1 are never statistically significant instead. Columns 4-6 of both panels refer to the second temporal interval (10am-1pm). The interaction terms appear negative and statistically significant. An increase of $10 \%$ in the EUR/SFr exchange rate is associated with a 1.6-1.8\% increase in the number of cars at late morning along the border ( 6 additional cars per hour and per traffic counting station). The cross-border shopping hypothesis explains these results. The stronger the Swiss franc, the higher the number of trips made by Swiss consumers to less expensive Italian shops. ${ }^{6}$

\subsection{Results on the car accident probability and air pollution}

Table 5 presents the results on the concentration of NOx in the air. For any temporal interval there are again two columns, one for working days and one for non-working days. The table shows that the exchange rate positively affected the concentration of NOx in the air, especially at peak hours, on working days. A $10 \%$ appreciation increased NOx emissions of $3.4 \%$ and $3.1 \%$ on working days, during early morning and the afternoon (columns 1 and 5 ), respectively. These are the same time intervals for which an increase in traffic flows - probably related to the larger number of cross-border commuters - is observed. Since the exchange rate effect on traffic flows for these temporal interval is found to be $1.6 \%-2.7 \%$, the elasticity of the concentration of NOx to traffic flows turns out to range from 1.2 to $1.9 \%$. For the time interval 10am-1pm, for both working days and non-working days, no effect is found (columns 3 and 4). This is explained by the fact that the level of NOx emissions is mostly associated with congestion.

\footnotetext{
${ }^{6}$ In the appendix Table A.1 presents the results regarding night traffic flows.
} 
During late morning, the rise in traffic flows - probably related to the effect of the appreciation on cross-border shopping- was not large enough to decrease traffic speeds and, consequently, had no effect on air quality.

When I analyse the effect on the monthly car accident probability, I find evidence of a different pattern. I distinguish between car accidents with minor personal injuries (Table 6), with severe personal injuries (Table 7) and with material damages (Table 8). While no effect is found for car accidents with severe personal injuries or with material damages, the interaction term turns out to be negative and statistically significant in Table 6 in column 4, which speaks at car accidents with mild personal injuries occurring during the second time interval (10am$1 \mathrm{pm}$ ) on non-working days. A $10 \%$ appreciation of the Swiss franc is associated with a 1.2 percentage points increase in the monthly probability of a car accident with minor personal injuries. In percentage terms, this corresponds to an $8 \%$ increase. Given a traffic volume of, on average, 300 cars per hour, an increase of $1.6 \%$ in the number of vehicles produces a more than proportional increase in the car accident probability with personal injuries- the elasticity of the probability of a car accident with minor personal injuries to the traffic is around $4 .{ }^{7}$ On the other hand, the rise in traffic flows found on working days during early morning and the evening, which are time-intervals characterized by very high levels of congestion, equal around 560 cars per hour, and presumably low traffic speed, does not translate into an increase in the risk of car accidents (columns 1 and 5). ${ }^{8}$

\section{$4 \quad$ IV Strategy}

In the previous section, in order to estimate the effect of traffic on the car accident probability and air pollution, I exploit exogenous variation in traffic flows associated with the Swiss franc appreciation and implement a 3 -step procedure. I first estimate the effect of the exchange rate on traffic flows. Then, I investigate the effect that the exchange rate has on the car accident probability and air pollution. In the final step, using both previous estimates, I compute the elasticity of the car accident probability and concentration of oxides of nitrogen to the number of cars. The hypothesis is that the appreciation leads to a change in my variables of interests (car accident and air pollution) only through the increase in traffic flows.

\footnotetext{
${ }^{7}$ The estimated elasticity is in line with previous studies. Romem and Shurtz (2016) estimates an elasticity of accidents to traffic equals 2 , while Edlin and Karaca-Mandic (2006) estimates that the external accident costs range from 2 to 4 .

${ }^{8}$ In the Appendix, Table A.2, Table A.3, Table A.4, Table A.5 present the results for accidents occurring at night
} 
This strategy is similar to a 2-stage least squares estimation in which the exchange rate is used an instrument. Since the exchange rate is associated with changes in traffic volume but does not directly affect car accidents and air pollution, the exchange rate indeed represents a valid instrument for the number of cars on the roads.

Then, in order to check the robustness of my results, I also implement an IV strategy. However, in order to implement such a strategy, a clear correspondence between traffic-counting stations, municipalities ${ }^{9}$ and air quality monitoring stations is needed. The data on traffic flows and air pollution come from 24 traffic counting stations and 16 air-monitoring stations, respectively. The number of accidents are reported for 136 municipalities instead. From this follows that in order to implement an IV strategy for the analysis on car accidents, I need to restrict my analysis to a sample of municipalities, consisting of those in which at least one traffic counting station is located. I end up with 23 municipalities. ${ }^{10}$ For the analysis regarding air pollution, I identify, for each air-monitoring station, the closer traffic counting stations instead. Each air monitoring station can indeed be linked to one or more traffic counting stations. ${ }^{11}$ I perform a 2SLS estimation, using Equations 2 and 3, respectively, for the NOx concentration and the car accident probability and the exchange rate as an instrument for the traffic flows.

The results are shown in Table 9- Table 12. Table 9 regards the estimates on air pollution, while Table 10, Table 11, Table 12 speak at the probability of car accidents with minor personal injuries, severe personal injuries and material damages, respectively. The results for all the variables of interests are similar to those provided in Section 3. An increase in traffic flows is associated with an increase in the concentration of NOx only in early morning and in the evening on working days. Moreover, the increase in traffic flows is shown to lead to an increase in the probability of a car accident with mild personal injuries at late morning on non-working days. The use of the instrument slightly decreases my estimates. The estimated elasticity of air pollution to traffic is $0.9 \%$ compared to $1.2 \%$, estimated in Section 3 (for early morning). The elasticity of car accidents to the number of cars, turns out to be $2.1 \%$ instead of $4 \%$. The different sample used for this analysis can explain the difference in the estimates. ${ }^{12}$

\footnotetext{
${ }^{9}$ the municipality is the unit of the accident dataset

${ }^{10}$ Two traffic-counting stations are located in the same municipality.

${ }^{11}$ For two air-monitoring stations, this association is not feasible as they are far from all traffic-counting stations. These air-monitoring stations are those located in Megadino and Comano.

${ }^{12}$ The results of the analysis for the night are reported in the Appendix in Table A.6 - Table A.9
} 


\section{Discussion}

In the previous sections, I estimate the effect that an increase in traffic flows has on the car accident probability and the air quality and show that the magnitude of the effect largely depends on the initial number of cars on the roads. To do so, I exploit exogenous variation in traffic flows associated with the Swiss-franc appreciation and geographical variation in traffic counting stations. My claim is that municipalities that are located closer to the border are more affected by the increase in cross-border commuting and cross-border shopping following the Swiss franc appreciation. This allows me to use a Difference-in-Differences estimator and to address the omitted variable problem that arises by directly regressing car accidents and air pollution on traffic.

However, since the value of the Swiss franc in euros increases during the financial crisis and then remains mainly constant until 2015, when it appreciates even more sharply, a concern might be that my results are driven by some other factor that had an ongoing trend during the sample period, rather than by the exchange rate. In order to address this issue, I proceed as follows: I run a regression similar to my main specification in which I replace the exchange rate with year dummies. In Figure 4, 5, 6, I show the plot of the coefficients of year dummies interacting with the Treatment dummy, for the traffic flows, car accident probability, and air pollution, respectively. For each variable, I focus only on the time intervals for which I find significant results in the previous section- early morning and the afternoon on working days for the number of cars on the roads and the NOx concentration, and late morning on nonworking days for the number of cars and the car accident probability. All figures clearly show that the coefficients regarding the period when the Swiss franc was relatively stable are almost not statistically significant. The coefficients become statistically significant and increase in magnitude in correspondence with appreciation of the Swiss franc relative to the euro. These results also provide evidence for a parallel trend in my variables of interests between the treatment group and the control group, before the beginning of the appreciation.

Another concern might be that I am capturing the effects of local economic activity and recovery after the 2008 financial crisis, rather than the effects of the Swiss franc appreciation. Since the economic activity should affect traffic flows similarly, regardless of the closeness to the border- especially in view of the fact I exclude from my analysis traffic-counting stations on highways, which are affected by trade-related traffic flows- it is unlikely that I am confounding the two effects. However, to deal with this point, I check that my results are robust to including

the unemployment rates in Lombardy and in Ticino as control variables instead of the Italian 
and the Swiss GDP. In line with my expectations, the results do not change. ${ }^{13}$

\section{Concluding remarks}

Car accidents are predicted to become the seventh leading cause of death by 2030 and air pollution has been declared the largest environmental health hazard in Europe. Understanding patterns in these variables is thus relevant for health policy.

The objective of the present work is to establish a causal relationship between traffic flows and both car accident risk and air pollution. To do so, this paper exploits variation in crossborder travel stemming from the Swiss franc's appreciation. The EUR/Sfr exchange rate, by affecting the labour supply decision of Italian cross-border workers and the propensity for Swiss consumers to shop abroad, is, in fact, an important predictor of the number of cars crossing the Swiss-Italian border (Bello, 2019).

The results of this paper show that the appreciation of the Swiss franc was associated with a rise in the probability of a traffic accident and in the concentration of nitrogen oxides in the air, occurring simultaneously to an increase in traffic flows, during specific time-intervals and weekdays. While the effect for the NOx concentration is found at peak hours on working days, the rise in the car accident probability is observed only on non-working days at late morning. Differences in the initial level of traffic flows across weekdays and hours of the day might explain the result. At peak hours on weekdays, when roads are characterized by very high levels of congestion, the Swiss franc appreciation, by further increasing traffic flows, negatively affected air quality but did not increase the probability of a car accident. Conversely, on nonworking days at late morning, the higher number of cars on the road increased the risk of a road accident; however, being not enough to reduce traffic speed, it did not significantly affect the level of air pollution. Importantly, the exchange rate effects on both my variables of interests are found to be larger than the correspondent effects on traffic flows registered for the same time-intervals, providing evidence of a harmful externality.

These findings have important implications for governments and public policies that aim to promote road safety, improve air quality and implement optimal road pricing schemes.

\footnotetext{
${ }^{13}$ They are available upon request.
} 


\section{References}

Bello, Piera. 2019. "Exchange rate effects on cross-border commuting: evidence from the Swiss-Italian border." Journal of Economic Geography forthcoming.

Bertoli, Paola, Veronica Grembi, and Judit Vall Castello. 2018. "Not all silver lining? The Great Recession and road traffic accidents." Regional Science and Urban Economics 70:274288.

Dickerson, Andrew, John Peirson, and Roger Vickerman. 2000. "Road accidents and traffic flows: an econometric investigation." Economica 67 (265):101-121.

Edlin, Aaron S and Pinar Karaca-Mandic. 2006. "The accident externality from driving." Journal of Political Economy 114 (5):931-955.

Granados, José A Tapia. 2005. "Recessions and mortality in Spain, 1980-1997." European Journal of Population 21 (4):393-422.

Grossman, Gene M and Alan B Krueger. 1991. "Environmental impacts of a North American free trade agreement." Tech. rep., National Bureau of Economic Research.

Romem, Issi and Ity Shurtz. 2016. "The accident externality of driving: Evidence from observance of the Jewish Sabbath in Israel." Journal of Urban Economics 96:36-54.

Ruhm, Christopher J. 2000. "Are recessions good for your health?" The Quarterly journal of economics 115 (2):617-650.

Tihansky, Dennis P. 1974. "Impact of the energy crisis on traffic accidents." Transportation research 8 (4):481-492.

Viard, V Brian and Shihe Fu. 2015. "The effect of Beijing's driving restrictions on pollution and economic activity." Journal of Public Economics 125:98-115.

Wagenaar, Alexander C. 1984. "Effects of macroeconomic conditions on the incidence of motor vehicle accidents." Accident Analysis 8 Prevention 16 (3):191-205. 
Figures 
Figure 1: Distribution of traffic counting stations and air monitoring stations

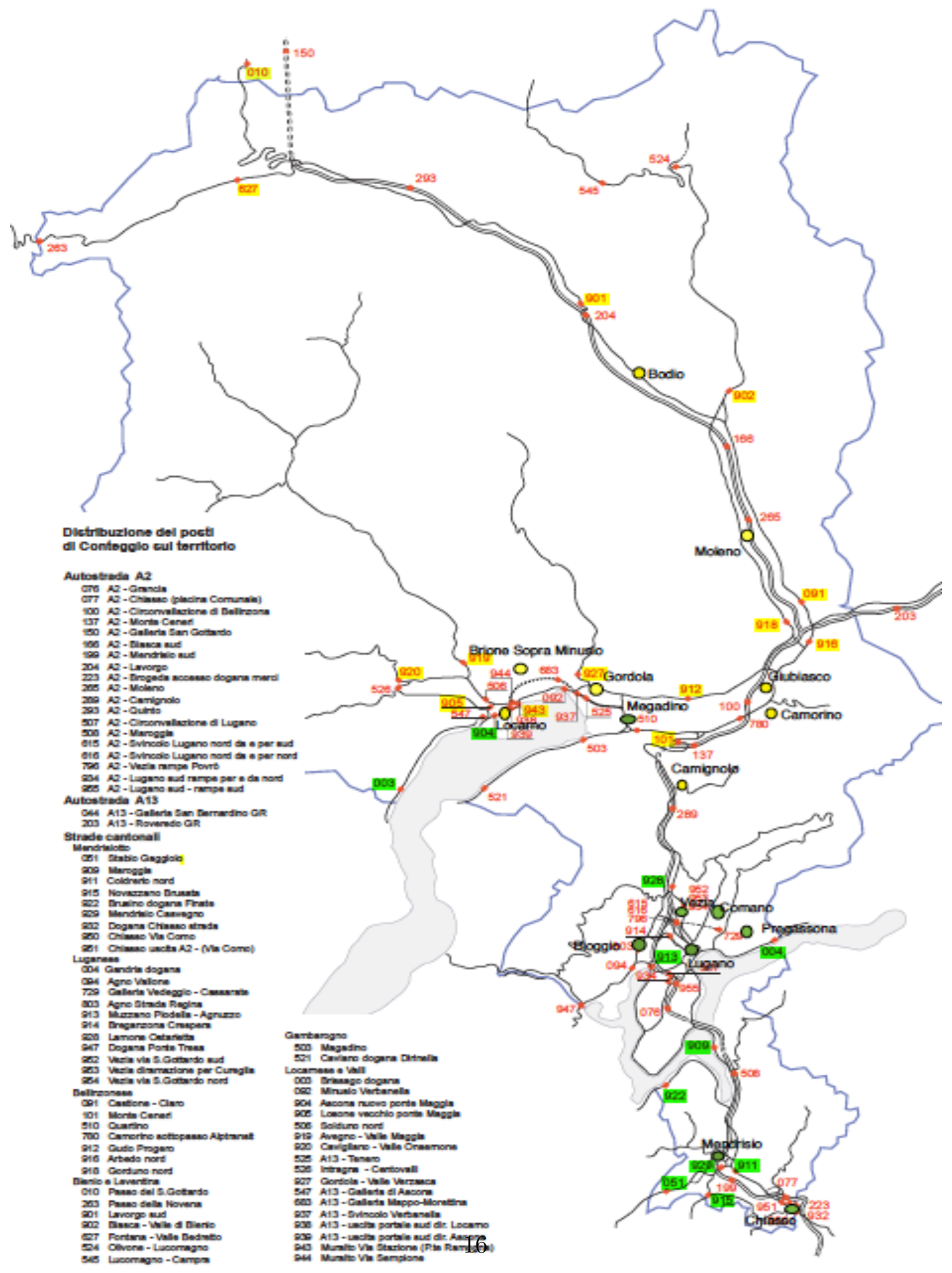

Note. The map shows where the traffic counting stations and the air monitoring stations are located. The Treatment Group consists of the traffic counting stations (underlined in green on the map) or air monitoring stations (indicated by a green dot on the map) located within $10 \mathrm{~km}$ of the border, and the Control Group includes the rest of the traffic counting stations (underlined in yellow on the map) or air monitoring stations (indicated by a yellow dot on the map). 
Figure 2: EUR/CHF Exchange rate, 2000-2015

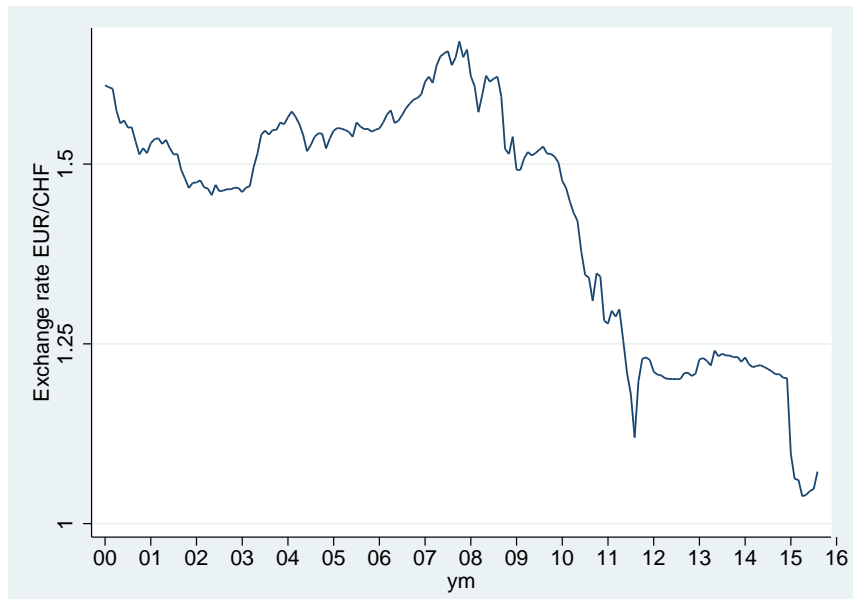

Notes: The figure presents the evolution of the EUR/SFr exchange rate, i.e. the value of the Euro in terms of the Swiss franc. The horizontal axis represents the time in months, from 2000 through 2015.

Figure 3: Annual and monthly variations in traffic flows

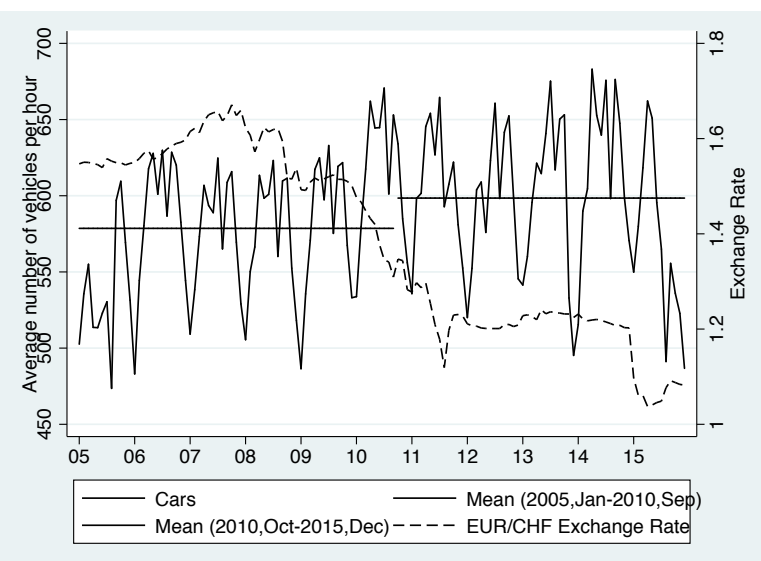

(a) Treatment $(<11 \mathrm{~km})$

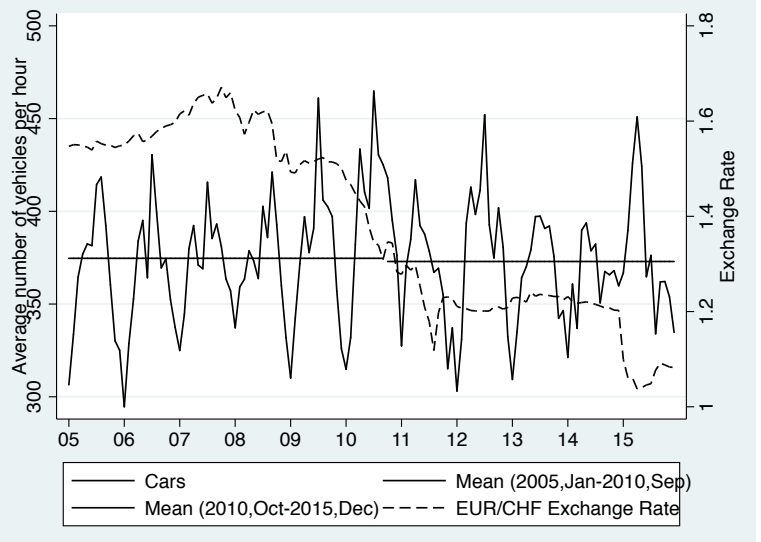

(b) Control (>10 km)

Notes: The figures show how the average number of cars per hour and per traffic-counting station changed over time across the two groups of traffic-counting stations. The symbol ' $\mathrm{CH}->\mathrm{IT}$ ' indicates north-to-south flows, and 'IT- $>\mathrm{CH}$ ' indicates south-to-north flows. The first group (Treatment) includes traffic-counting stations located within a driving distance of up to $10 \mathrm{~km}$ from the border, and the second group (Control) includes the remaining traffic-counting stations. The two straight lines represent the average number of cars in two periods: January 2005-September 2010 and October 2011-December 2015. Source: Sezione Mobilità del Canton Ticino (2005-2015). 
Figure 4: Plot of the Year by Year Regression Coefficients, Traffic Flows

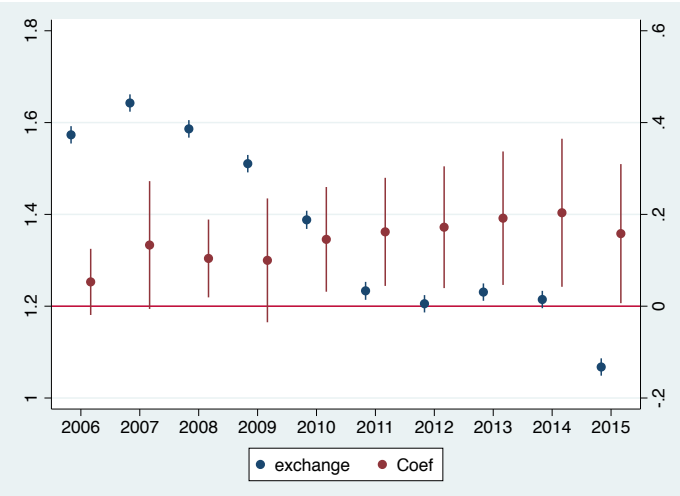

(a) 5am-9am, Working Days, IT->CH

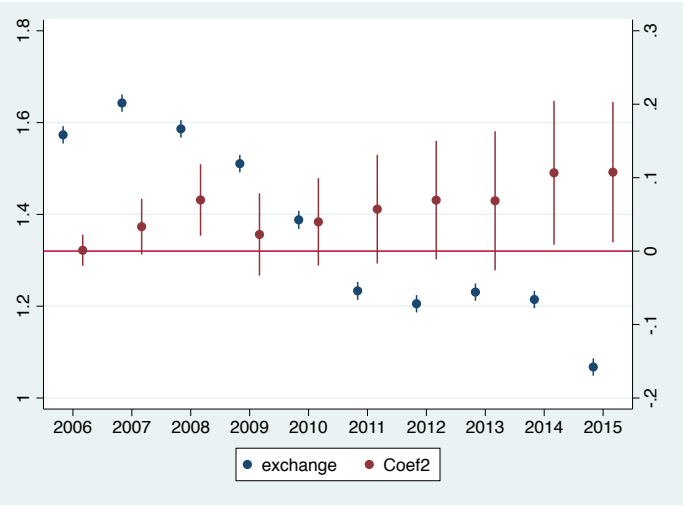

(b) 2pm-8pm, Working Days, CH->IT

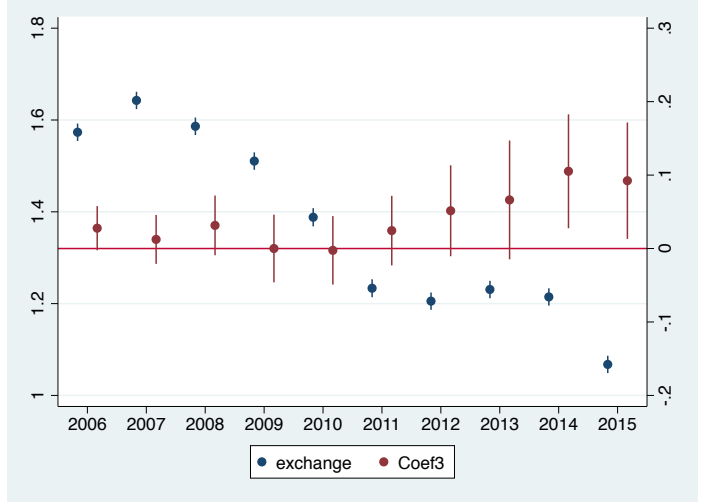

(c) 10am-1pm, NonWorking Days, CH->IT

Notes: Plot of the coefficients of interaction variables of the following equation Cars $_{i h m y}=\alpha+\sum_{n=2006}^{2015} \beta_{n} Y e a r_{n y}+$ $\sum_{n=2006}^{2015} \gamma_{n}$ Year $_{n y} *$ Treat $_{i}+\eta_{1} X_{m y}+f_{i}+m_{m}+\epsilon_{i h m y}$, where Cars $_{i h m y}$ is the log of the average number of cars crossing the traffic-counting station $i$ at hour $h$, month $m$ and year $y \cdot \sum_{n=2006}^{2015}$ year $n y$ represents year dummies for the years 20062015 and Treat $_{i}$ is a dummy for traffic-counting stations located within $10 \mathrm{~km}$ of the border. $\sum_{n=2006}^{2015}$ year $_{n y} *$ Trear $_{i}$ indicates the interaction terms between year dummies and the Trear dummy. $X_{m y}$ is the vector of control variables: the $\log$ of the Swiss GDP, the log of the Italian GDP, and the log of the Lombardy unemployment rate. Finally, $m_{m}$ and $f_{i}$ indicate month fixed effects and traffic-counting station fixed effects, respectively. The graph also shows the value of the EUR/CH exchange rate over time. Source: Sezione Mobilità del Canton Ticino (2005-2015). 
Figure 5: Plot of the Year by Year Regression Coefficients, Pollution

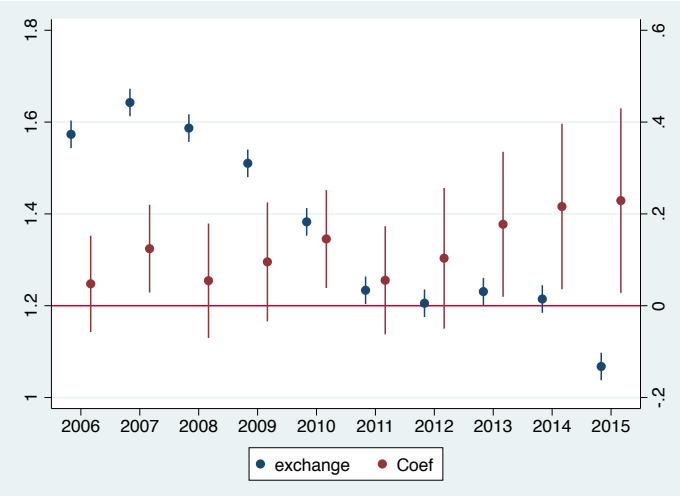

(a) 5am-9am, Working Days

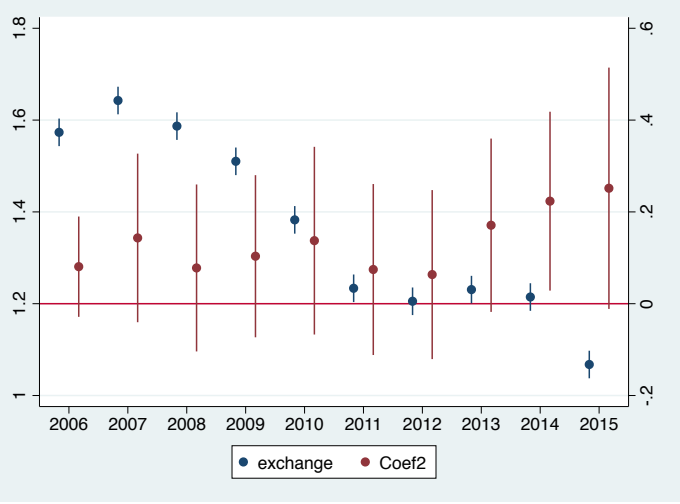

(b) 2pm-8pm, Working Days

Notes: Plot of the coefficients of interaction variables of the following equation Poll $_{i h m y}=\alpha+\sum_{n=2006}^{2015} \beta_{n} Y e a r_{n y}+$ $\sum_{n=2006}^{2015} \gamma_{n}$ Year $_{n y} *$ Treat $_{i}+\eta_{1} X_{m y}+f_{i}+m_{m}+\epsilon_{i h m y}$, where Poll $i h m y$ is the log of the monthly concentrations of NOx in municipality $i$ at hour $h$, month $m$ and year $y . \sum_{n=2006}^{2015}$ year $_{n y}$ represents year dummies for the years 2006-2015 and Treat $_{i}$ is a dummy for traffic-counting stations located within $10 \mathrm{~km}$ of the border. $\sum_{n=2006}^{2015}$ year $_{n y} *$ Trear $_{i}$ indicates the interaction terms between year dummies and the Treat dummy. $X_{m y}$ is the vector of control variables: the log of the Swiss GDP, the log of the Italian GDP, and the log of the Lombardy unemployment rate. Finally, $m_{m}$ and $f_{i}$ indicate month fixed effects and traffic-counting station fixed effects, respectively. The graph also shows the value of the EUR/CH exchange rate over time. Source:Sezione Mobilità del Canton Ticino (2005-2015).

Figure 6: Plot of the Year by Year Regression Coefficients, Car Accidents

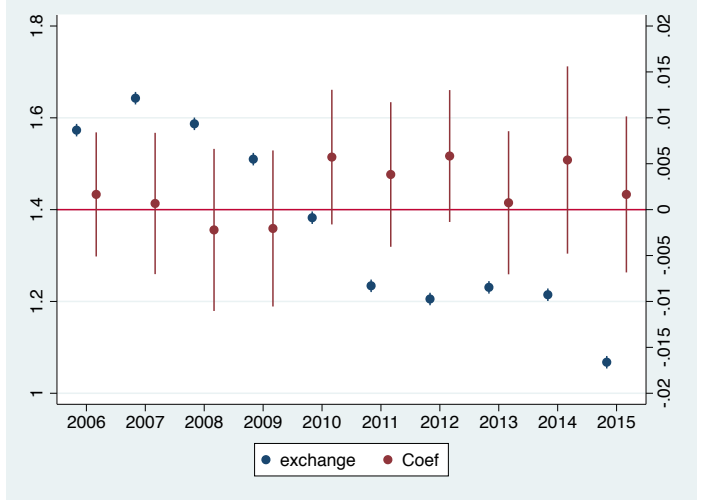

(a) 10am-1pm, Non-Work. Days

Notes: Plot of the coefficients of interaction variables of the following equation $A_{c c} c_{i m y}=\alpha+\sum_{n=2006}^{2015} \beta_{n} Y e a r_{n y}+$ $\sum_{n=2006}^{2015} \gamma_{n}$ Year $_{n y} *$ Treat $_{i}+\eta_{1} X_{m y}+f_{i}+m_{m}+\epsilon_{i h m y}$, where $A c c_{i h m y}$ is a dummy variable that takes value 1 if at least one accident occurs in municipality $i$ at hour $h$, month $m$ and year $y . \sum_{n=2006}^{2015}$ year $_{n y}$ represents year dummies for the years 2006-2015 and Treat $_{i}$ is a dummy for traffic-counting stations located within $10 \mathrm{~km}$ of the border. $\sum_{n=2006}^{2015}$ year $_{n y} *$ Trear $_{i}$ indicates the interaction terms between year dummies and the Treat dummy. $X_{m y}$ is the vector of control variables: the log of the Swiss GDP, the log of the Italian GDP, and the log of the Lombardy unemployment rate. Finally, $m_{m}$ and $f_{i}$ indicate month fixed effects and traffic-counting station fixed effects, respectively. The graph also shows the value of the EUR/CH exchange rate over time. Source: Federal Roads Office (2005-2015). 


\section{Tables}

Table 1: Descriptive statistics on the average number of cars

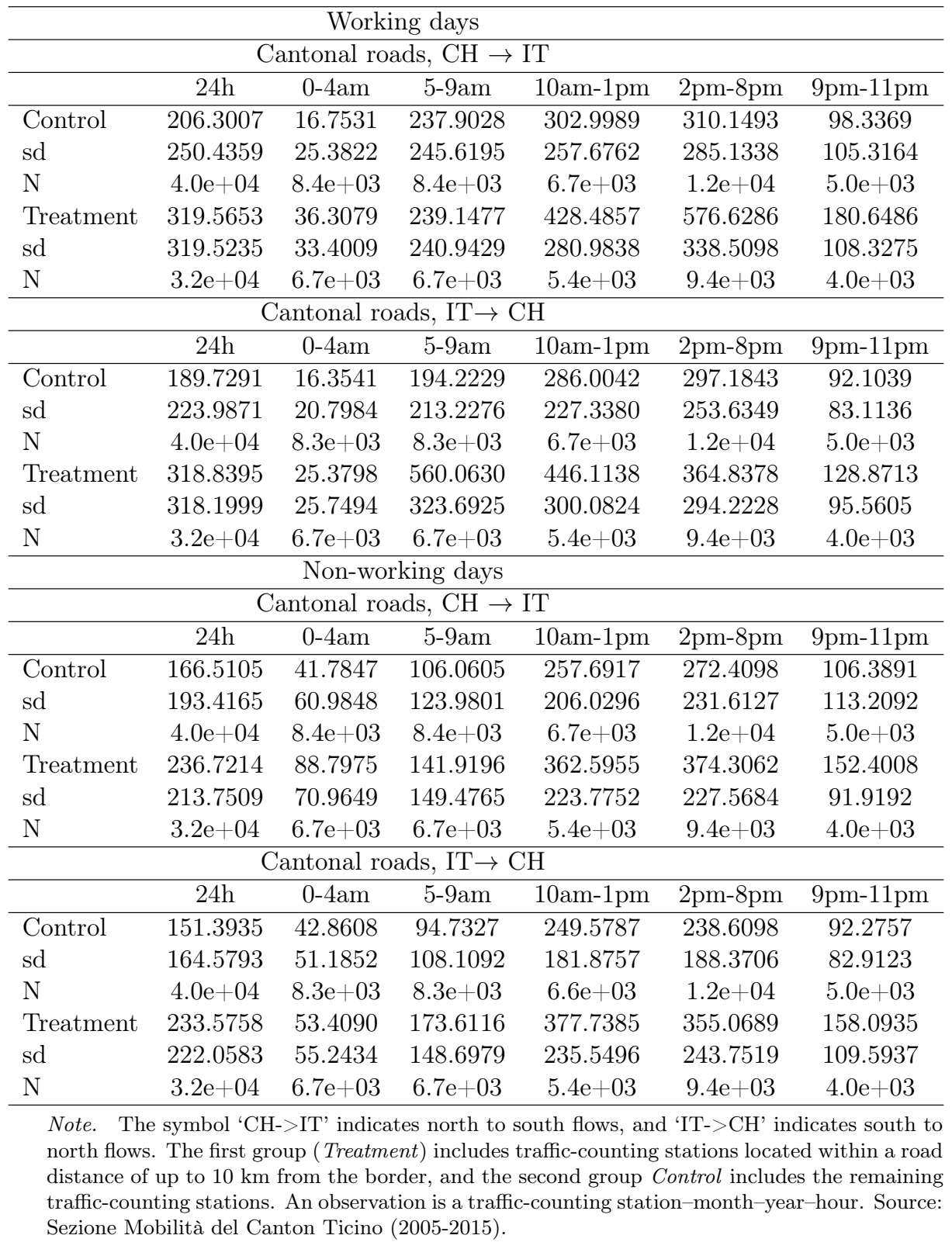


Table 2: Descriptive statistics: Monthly average concentration of nitrogen oxides (NOx)

\begin{tabular}{|c|c|c|c|c|c|c|}
\hline \multicolumn{7}{|c|}{ Nox } \\
\hline \multicolumn{7}{|c|}{ Working days } \\
\hline & $24 \mathrm{~h}$ & $0-4 \mathrm{am}$ & 5-9am & $10 \mathrm{am}-1 \mathrm{pm}$ & $2 \mathrm{pm}-8 \mathrm{pm}$ & $9 \mathrm{pm}-11 \mathrm{pm}$ \\
\hline Control & 53.4663 & 23.7689 & 81.8830 & 48.3223 & 60.4439 & 46.1315 \\
\hline sd & 53.2334 & 21.0035 & 71.0761 & 38.0937 & 54.1928 & 41.3596 \\
\hline $\mathrm{N}$ & $1.4 \mathrm{e}+04$ & $3.0 \mathrm{e}+03$ & $3.0 \mathrm{e}+03$ & $2.4 \mathrm{e}+03$ & $4.2 \mathrm{e}+03$ & $1.8 \mathrm{e}+03$ \\
\hline Treatment & 35.6259 & 20.3007 & 52.9112 & 33.3734 & 35.9428 & 34.6466 \\
\hline sd & 34.6756 & 19.1396 & 45.2623 & 27.1910 & 34.0189 & 31.8499 \\
\hline $\mathrm{N}$ & $1.9 \mathrm{e}+04$ & $3.9 \mathrm{e}+03$ & $3.9 \mathrm{e}+03$ & $3.1 \mathrm{e}+03$ & $5.5 \mathrm{e}+03$ & $2.4 \mathrm{e}+03$ \\
\hline \multicolumn{7}{|c|}{ Nonworking days } \\
\hline & $24 \mathrm{~h}$ & $0-4 a m$ & 5-9am & $10 \mathrm{am}-1 \mathrm{pm}$ & $2 \mathrm{pm}-8 \mathrm{pm}$ & $9 \mathrm{pm}-11 \mathrm{pm}$ \\
\hline Control & 36.2449 & 29.6710 & 46.3703 & 30.3626 & 37.1198 & 36.1160 \\
\hline sd & 31.5219 & 24.0939 & 39.3376 & 24.4356 & 32.9113 & 28.0964 \\
\hline $\mathrm{N}$ & $1.4 \mathrm{e}+04$ & $3.0 \mathrm{e}+03$ & $3.0 \mathrm{e}+03$ & $2.4 \mathrm{e}+03$ & $4.2 \mathrm{e}+03$ & $1.8 \mathrm{e}+03$ \\
\hline Treatment & 21.8507 & 22.1256 & 25.6033 & 17.6029 & 20.5729 & 23.7834 \\
\hline sd & 19.4383 & 19.7122 & 20.6704 & 14.6996 & 19.8360 & 20.0572 \\
\hline $\mathrm{N}$ & $1.9 \mathrm{e}+04$ & $3.9 \mathrm{e}+03$ & $3.9 \mathrm{e}+03$ & $3.1 \mathrm{e}+03$ & $5.5 \mathrm{e}+03$ & $2.3 \mathrm{e}+03$ \\
\hline
\end{tabular}

Note. Years 2005-2015. Data are expressed in ppb (parts per million). The Treatment Group consists of monitoring stations in municipalities within $10 \mathrm{~km}$ of the border, the Control Group includes the rest of stations. An observation is an air monitoring station-month-hour. Source: Sezione Mobiltà Canton Ticino.

Table 3: Descriptive statistics on the monthly average probability of a car accident

\begin{tabular}{|c|c|c|c|c|c|c|}
\hline \multicolumn{7}{|c|}{ Accidents with minor personal injuries } \\
\hline \multicolumn{7}{|c|}{ Working days } \\
\hline & $24 \mathrm{~h}$ & $0-4 a m$ & 5-9am & $10 \mathrm{am}-1 \mathrm{pm}$ & $2 \mathrm{pm}-8 \mathrm{pm}$ & 9pm-11pm \\
\hline Control & 0.0106 & 0.0042 & 0.0086 & 0.0154 & 0.0159 & 0.0059 \\
\hline sd & 0.1025 & 0.0647 & 0.0926 & 0.1231 & 0.1250 & 0.0768 \\
\hline $\mathrm{N}$ & $2.8 \mathrm{e}+05$ & $5.8 \mathrm{e}+04$ & $5.8 \mathrm{e}+04$ & $4.6 \mathrm{e}+04$ & $8.1 e+04$ & $3.5 \mathrm{e}+04$ \\
\hline Treatment & 0.0190 & 0.0070 & 0.0179 & 0.0266 & 0.0280 & 0.0098 \\
\hline sd & 0.1366 & 0.0834 & 0.1326 & 0.1609 & 0.1651 & 0.0987 \\
\hline $\mathrm{N}$ & $1.5 \mathrm{e}+0.5$ & $3.2 \mathrm{e}+04$ & $3.2 \mathrm{e}+04$ & $2.5 \mathrm{e}+04$ & $4.4 \mathrm{e}+04$ & $1.9 \mathrm{e}+04$ \\
\hline \multicolumn{7}{|c|}{ Non-Working Days } \\
\hline & $24 \mathrm{~h}$ & $0-4 \mathrm{am}$ & 5-9am & $10 \mathrm{am}-1 \mathrm{pm}$ & $2 \mathrm{pm}-8 \mathrm{pm}$ & $9 \mathrm{pm}-11 \mathrm{pm}$ \\
\hline Control & 0.0052 & 0.0016 & 0.0046 & 0.0073 & 0.0076 & 0.0034 \\
\hline sd & 0.0716 & 0.0400 & 0.0679 & 0.0854 & 0.0868 & 0.0578 \\
\hline $\mathrm{N}$ & $2.8 \mathrm{e}+05$ & $5.8 \mathrm{e}+04$ & $5.8 \mathrm{e}+04$ & $4.6 \mathrm{e}+04$ & $8.1 \mathrm{e}+04$ & $3.5 \mathrm{e}+04$ \\
\hline Treatment & 0.0093 & 0.0034 & 0.0087 & 0.0123 & 0.0139 & 0.0049 \\
\hline sd & 0.0957 & 0.0580 & 0.0931 & 0.1103 & 0.1171 & 0.0702 \\
\hline $\mathrm{N}$ & $1.5 \mathrm{e}+05$ & $3.2 \mathrm{e}+04$ & $3.2 \mathrm{e}+04$ & $2.5 \mathrm{e}+04$ & $4.4 \mathrm{e}+04$ & $1.9 \mathrm{e}+04$ \\
\hline
\end{tabular}




\begin{tabular}{|c|c|c|c|c|c|c|}
\hline \multicolumn{7}{|c|}{ Accidents with severe personal injuries } \\
\hline \multicolumn{7}{|c|}{ Working days } \\
\hline $24 \mathrm{~h}$ & $0-4 \mathrm{am}$ & $5-9 \mathrm{am}$ & 10am-1pm & $2 \mathrm{pm}-8 \mathrm{pm}$ & $9 \mathrm{pm}-11 \mathrm{pm}$ & \\
\hline Control & 0.0037 & 0.0014 & 0.0028 & 0.0053 & 0.0059 & 0.0019 \\
\hline sd & 0.0610 & 0.0378 & 0.0527 & 0.0726 & 0.0768 & 0.0435 \\
\hline $\mathrm{N}$ & $2.8 \mathrm{e}+05$ & $5.8 \mathrm{e}+04$ & $5.8 \mathrm{e}+04$ & $4.6 \mathrm{e}+04$ & $8.1 \mathrm{e}+04$ & $3.5 \mathrm{e}+04$ \\
\hline Treatment & 0.0079 & 0.0029 & 0.0070 & 0.0099 & 0.0123 & 0.0045 \\
\hline sd & 0.0883 & 0.0541 & 0.0834 & 0.0992 & 0.1101 & 0.0667 \\
\hline $\mathrm{N}$ & $1.5 \mathrm{e}+05$ & $3.2 \mathrm{e}+04$ & $3.2 \mathrm{e}+04$ & $2.5 \mathrm{e}+04$ & $4.4 \mathrm{e}+04$ & $1.9 \mathrm{e}+04$ \\
\hline \multicolumn{7}{|c|}{ Nonworking days } \\
\hline & $24 \mathrm{~h}$ & $0-4 \mathrm{am}$ & 5-9am & $10 \mathrm{am}-1 \mathrm{pm}$ & $2 \mathrm{pm}-8 \mathrm{pm}$ & 9pm-11pm \\
\hline Control & 0.0018 & 0.0008 & 0.0012 & 0.0023 & 0.0030 & 0.0009 \\
\hline sd & 0.0419 & 0.0281 & 0.0342 & 0.0475 & 0.0544 & 0.0298 \\
\hline $\mathrm{N}$ & $2.8 \mathrm{e}+05$ & $5.8 \mathrm{e}+04$ & $5.8 \mathrm{e}+04$ & $4.6 \mathrm{e}+04$ & $8.1 \mathrm{e}+04$ & $3.5 \mathrm{e}+04$ \\
\hline Treatment & 0.0040 & 0.0016 & 0.0031 & 0.0053 & 0.0064 & 0.0021 \\
\hline sd & 0.0631 & 0.0401 & 0.0558 & 0.0725 & 0.0796 & 0.0458 \\
\hline $\mathrm{N}$ & $1.5 \mathrm{e}+05$ & $3.2 \mathrm{e}+04$ & $3.2 \mathrm{e}+04$ & $2.5 \mathrm{e}+04$ & $4.4 \mathrm{e}+04$ & $1.9 \mathrm{e}+04$ \\
\hline \multicolumn{7}{|c|}{ Accidents with material damages } \\
\hline \multicolumn{7}{|c|}{ Working days } \\
\hline $24 \mathrm{~h}$ & $0-4 \mathrm{am}$ & $5-9 \mathrm{am}$ & 10am-1pm & $2 \mathrm{pm}-8 \mathrm{pm}$ & 9pm-11pm & \\
\hline Control & 0.0508 & 0.0240 & 0.0455 & 0.0648 & 0.0683 & 0.0443 \\
\hline sd & 0.2195 & 0.1532 & 0.2084 & 0.2462 & 0.2523 & 0.2058 \\
\hline $\mathrm{N}$ & $2.8 \mathrm{e}+05$ & $5.8 \mathrm{e}+04$ & $5.8 \mathrm{e}+04$ & $4.6 \mathrm{e}+04$ & $8.1 \mathrm{e}+04$ & $3.5 \mathrm{e}+04$ \\
\hline Treatment & 0.0724 & 0.0317 & 0.0640 & 0.1018 & 0.1008 & 0.0485 \\
\hline sd & 0.2591 & 0.1752 & 0.2448 & 0.3023 & 0.3010 & 0.2148 \\
\hline $\mathrm{N}$ & $1.5 \mathrm{e}+05$ & $3.2 \mathrm{e}+04$ & $3.2 \mathrm{e}+04$ & $2.5 \mathrm{e}+04$ & $4.4 \mathrm{e}+04$ & $1.9 \mathrm{e}+04$ \\
\hline \multicolumn{7}{|c|}{ Nonworking days } \\
\hline & $24 \mathrm{~h}$ & $0-4 \mathrm{am}$ & 5-9am & $10 \mathrm{am}-1 \mathrm{pm}$ & $2 \mathrm{pm}-8 \mathrm{pm}$ & 9pm-11pm \\
\hline Control & 0.0257 & 0.0117 & 0.0224 & 0.0330 & 0.0353 & 0.0228 \\
\hline sd & 0.1583 & 0.1076 & 0.1479 & 0.1785 & 0.1845 & 0.1494 \\
\hline $\mathrm{N}$ & $2.8 \mathrm{e}+05$ & $5.8 \mathrm{e}+04$ & $5.8 \mathrm{e}+04$ & $4.6 \mathrm{e}+04$ & $8.1 \mathrm{e}+04$ & $3.5 \mathrm{e}+04$ \\
\hline Treatment & 0.0391 & 0.0176 & 0.0332 & 0.0556 & 0.0538 & 0.0283 \\
\hline sd & 0.1938 & 0.1314 & 0.1791 & 0.2291 & 0.2256 & 0.1658 \\
\hline $\mathrm{N}$ & $1.5 \mathrm{e}+05$ & $3.2 \mathrm{e}+04$ & $3.2 \mathrm{e}+04$ & $2.5 \mathrm{e}+04$ & $4.4 \mathrm{e}+04$ & $1.9 \mathrm{e}+04$ \\
\hline
\end{tabular}

Note. Years 2005-2015. The Treatment Group consists of municipalities within $10 \mathrm{~km}$ of the border, the Control Group includes the rest of municipalities. An observation is a municipalitymonth-hour. Source: Federal Roads Office. 
Table 4: Monthly average number of cars

\begin{tabular}{|c|c|c|c|c|c|c|}
\hline \multicolumn{7}{|c|}{ Panel 1: IT $\rightarrow$ CH, Day } \\
\hline & (1) & $(2)$ & $(3)$ & (4) & (5) & (6) \\
\hline & Mon-Fri & Sat-Sun & Mon-Fri & Sat-Sun & Mon-Fri & Sat-Sun \\
\hline & $5 \mathrm{am}-9 \mathrm{am}$ & $5 \mathrm{am}-9 \mathrm{am}$ & $10 \mathrm{am}-1 \mathrm{pm}$ & $10 \mathrm{am}-1 \mathrm{pm}$ & $2 \mathrm{pm}-8 \mathrm{pm}$ & $2 \mathrm{pm}-8 \mathrm{pm}$ \\
\hline \multirow[t]{2}{*}{$\ln \mathrm{e}$} & -0.137 & 0.049 & -0.010 & 0.025 & -0.083 & -0.039 \\
\hline & $(0.118)$ & $(0.097)$ & $(0.060)$ & $(0.070)$ & $(0.067)$ & $(0.063)$ \\
\hline \multirow[t]{2}{*}{ Treatment* $\ln$ e } & $-0.266^{*}$ & $-0.269^{* *}$ & $-0.161^{*}$ & -0.111 & 0.020 & 0.112 \\
\hline & $(0.136)$ & $(0.116)$ & $(0.083)$ & $(0.088)$ & $(0.087)$ & $(0.089)$ \\
\hline Observations & 15,037 & 15,015 & 12,040 & 12,024 & 21,063 & 21,032 \\
\hline R-squared & 0.710 & 0.601 & 0.936 & 0.909 & 0.857 & 0.828 \\
\hline \multicolumn{7}{|c|}{ Panel 2: CH $\rightarrow$ IT, Day } \\
\hline & (1) & $(2)$ & $(3)$ & $(4)$ & $(5)$ & $(6)$ \\
\hline & Mon-Fri & Sat-Sun & Mon-Fri & Sat-Sun & Mon-Fri & Sat-Sun \\
\hline & $5 \mathrm{am}-9 \mathrm{am}$ & $5 \mathrm{am}-9 \mathrm{am}$ & $10 \mathrm{am}-1 \mathrm{pm}$ & $10 \mathrm{am}-1 \mathrm{pm}$ & $2 \mathrm{pm}-8 \mathrm{pm}$ & $2 \mathrm{pm}-8 \mathrm{pm}$ \\
\hline \multirow[t]{2}{*}{$\ln \mathrm{e}$} & -0.082 & -0.097 & -0.032 & 0.022 & -0.026 & 0.043 \\
\hline & $(0.086)$ & $(0.089)$ & $(0.052)$ & $(0.055)$ & $(0.072)$ & $(0.053)$ \\
\hline \multirow[t]{2}{*}{ Treatment* $\ln$ e } & -0.181 & -0.025 & $-0.177^{* *}$ & $-0.163^{* *}$ & $-0.165^{*}$ & -0.001 \\
\hline & $(0.158)$ & $(0.118)$ & $(0.069)$ & $(0.075)$ & $(0.085)$ & $(0.065)$ \\
\hline Observations & 15,100 & 15,089 & 12,087 & 12,080 & 21,145 & 21,129 \\
\hline R-squared & 0.647 & 0.555 & 0.942 & 0.917 & 0.825 & 0.828 \\
\hline Controls FE & YES & YES & YES & YES & YES & YES \\
\hline Monthly FE & YES & YES & YES & YES & YES & YES \\
\hline Station FE & YES & YES & YES & YES & YES & YES \\
\hline
\end{tabular}

Note. The dependent variable is the log of the monthly average number of cars crossing a specific station in a given hour. The symbol ' $\mathrm{CH}->\mathrm{IT}$ ' indicates north-to-south flows, and 'IT- $>\mathrm{CH}$ ' indicates south-tonorth flows. Treatment is a dummy for the traffic-counting stations located within a driving distance of up to $10 \mathrm{~km}$ from the border. Controls include the log of the Swiss GDP, the log of the Italian GDP, and the $\log$ of the unemployment rate in Lombardy. Monthly and traffic-counting station fixed effects, as well as a dummy for the period after 2007, are also included. Robust standard errors (in parentheses) are clustered at the traffic-counting station level. An observation is a traffic-counting station-month-year-hour. The following symbols indicate different significance levels: ${ }^{* *} \mathrm{p}<0.01,{ }^{* *} \mathrm{p}<0.05,{ }^{*} \mathrm{p}<0.1$. Source: Sezione Mobilità del Canton Ticino (2005-2015). 
Table 5: Monthly average concentration of nitrogen oxides (Nox, mg/m3), Day

\begin{tabular}{lcccccc}
\hline & $(1)$ & $(2)$ & $(3)$ & $(4)$ & $(5)$ & $(6)$ \\
& Wday & NWday & Wday & NWday & Wday & NWday \\
& 5am-9am & $5 \mathrm{am}-9 \mathrm{am}$ & $10 \mathrm{am}-1 \mathrm{pm}$ & $10 \mathrm{am}-1 \mathrm{pm}$ & $2 \mathrm{pm}-8 \mathrm{pm}$ & $2 \mathrm{pm}-8 \mathrm{pm}$ \\
\hline ln e & 0.078 & 0.061 & $0.326^{* * *}$ & -0.010 & $0.365^{* *}$ & -0.199 \\
& $(0.151)$ & $(0.146)$ & $(0.088)$ & $(0.152)$ & $(0.136)$ & $(0.207)$ \\
Treat*ln e & $-0.346^{* *}$ & -0.276 & -0.223 & -0.059 & $-0.312^{*}$ & 0.028 \\
& $(0.159)$ & $(0.161)$ & $(0.197)$ & $(0.163)$ & $(0.178)$ & $(0.172)$ \\
& & & & & & \\
Observations & 6,932 & 6,895 & 5,547 & 5,516 & 9,712 & 9,653 \\
R-squared & 0.722 & 0.842 & 0.791 & 0.801 & 0.849 & 0.819 \\
\hline Mun FE & YES & YES & YES & YES & YES & YES \\
Month FE & YES & YES & YES & YES & YES & YES \\
\hline
\end{tabular}

Note.Years 2005-2014. Data are expressed in parts per million (ppb). The dependent variable is the monthly average concentration of nitrogen oxides in a given hour. Treat is a dummy for monitoring stations in municipalities within $10 \mathrm{~km}$ of the border. I control for log of the Swiss GDP, log of the Italian GDP and $\log$ of the unemployment rate in Lombardy. Monthly and station fixed effects, and a dummy for the period after 2007 are also included. Robust standard errors in parentheses clustered at the monitoring station level. An observation is an air monitoring station-month-hour.

Table 6: Monthly probability of an accident, Day, With Minor Personal Injuries

\begin{tabular}{lcccccc}
\hline & $(1)$ & $(2)$ & $(3)$ & $(4)$ & $(5)$ & $(6)$ \\
& Wday & NWday & Wday & NWday & Wday & NWday \\
& 5am-9am & 5am-9am & $10 \mathrm{am}-1 \mathrm{pm}$ & $10 \mathrm{am}-1 \mathrm{pm}$ & $2 \mathrm{pm}-8 \mathrm{pm}$ & $2 \mathrm{pm}-8 \mathrm{pm}$ \\
\hline ln e & 0.002 & -0.001 & $0.023^{* * *}$ & 0.001 & 0.009 & 0.001 \\
& $(0.006)$ & $(0.007)$ & $(0.008)$ & $(0.006)$ & $(0.009)$ & $(0.006)$ \\
Treat*ln $\mathrm{e}$ & 0.000 & -0.006 & -0.012 & $-0.012^{* *}$ & -0.006 & -0.008 \\
& $(0.008)$ & $(0.004)$ & $(0.008)$ & $(0.006)$ & $(0.010)$ & $(0.005)$ \\
& & & & & & \\
Observations & 89,760 & 89,760 & 71,808 & 71,808 & 125,664 & 125,664 \\
R-squared & 0.056 & 0.027 & 0.087 & 0.043 & 0.088 & 0.044 \\
\hline Mun FE & YES & YES & YES & YES & YES & YES \\
Month FE & YES & YES & YES & YES & YES & YES \\
\hline
\end{tabular}

Note.Years 2005-2014. The dependent variable is a dummy variable equal to 1 if at least one car accident with minor personal injuries occurs in a given hour. Treat is a dummy for municipalities within $10 \mathrm{~km}$ of the border. I control for log of the Swiss GDP, log of the Italian GDP, log of the unemployment rate in Lombardy. Monthly and municipality fixed effects, and a dummy for the period after 2007 are also included. Robust standard errors in parentheses clustered at the municipal level. An observation is a municipality-month-hour. 
Table 7: Monthly probability of an accident, Day, With Severe Personal Injuries

\begin{tabular}{lcccccc}
\hline & $(1)$ & $(2)$ & $(3)$ & $(4)$ & $(5)$ & $(6)$ \\
& Wday & NWday & Wday & NWday & Wday & NWDAY \\
& 5am-9am & $5 \mathrm{am}-9 \mathrm{am}$ & $10 \mathrm{am}-1 \mathrm{pm}$ & $10 \mathrm{am}-1 \mathrm{pm}$ & $2 \mathrm{pm}-8 \mathrm{pm}$ & $2 \mathrm{pm}-8 \mathrm{pm}$ \\
\hline ln e & -0.001 & 0.002 & $0.009^{*}$ & -0.001 & -0.002 & -0.001 \\
& $(0.004)$ & $(0.002)$ & $(0.005)$ & $(0.004)$ & $(0.005)$ & $(0.003)$ \\
Treat*ln e & -0.000 & 0.002 & 0.006 & 0.004 & 0.004 & 0.003 \\
& $(0.004)$ & $(0.003)$ & $(0.009)$ & $(0.004)$ & $(0.005)$ & $(0.005)$ \\
& & & & & & \\
Observations & 89,760 & 89,760 & 71,808 & 71,808 & 125,664 & 125,664 \\
R-squared & 0.019 & 0.015 & 0.035 & 0.016 & 0.037 & 0.020 \\
\hline Mun FE & YES & YES & YES & YES & YES & YES \\
Month FE & YES & YES & YES & YES & YES & YES \\
\hline
\end{tabular}

Note.Years 2005-2014. The dependent variable is a dummy variable equal to 1 if at least one car accident with severe personal injuries occurs in a given hour. Treat is a dummy for municipalities within $10 \mathrm{~km}$ of the border. I control for log of the Swiss GDP, log of the Italian GDP, log of the unemployment rate in Lombardy. Monthly and municipality fixed effects, and a dummy for the period after 2007 are also included. Robust standard errors in parentheses clustered at the municipal level. An observation is a municipality-month-hour.

Table 8: Monthly probability of an accident, Day, With Material Damages

\begin{tabular}{lcccccc}
\hline & $(1)$ & $(2)$ & $(3)$ & $(4)$ & $(5)$ & $(6)$ \\
& Wday & NWday & Wday & NWday & Wday & NWDAY \\
& 5am-9am & 5am-9am & $10 \mathrm{am}-1 \mathrm{pm}$ & $10 \mathrm{am}-1 \mathrm{pm}$ & $2 \mathrm{pm}-8 \mathrm{pm}$ & $2 \mathrm{pm}-8 \mathrm{pm}$ \\
\hline ln e & -0.007 & -0.005 & $0.042^{* *}$ & 0.015 & $0.030^{*}$ & -0.002 \\
& $(0.013)$ & $(0.008)$ & $(0.020)$ & $(0.012)$ & $(0.017)$ & $(0.010)$ \\
Treat*ln e & 0.023 & 0.012 & -0.008 & -0.004 & 0.032 & 0.019 \\
& $(0.018)$ & $(0.011)$ & $(0.025)$ & $(0.015)$ & $(0.024)$ & $(0.015)$ \\
& & & & & & \\
Observations & 89,760 & 89,760 & 71,808 & 71,808 & 125,664 & 125,664 \\
R-squared & 0.123 & 0.079 & 0.240 & 0.189 & 0.210 & 0.160 \\
\hline Mun FE & YES & YES & YES & YES & YES & YES \\
Month FE & YES & YES & YES & YES & YES & YES \\
\hline
\end{tabular}

Note.Years 2005-2014. The dependent variable is a dummy variable equal to 1 if at least one car accident with material damages occurs in a given hour. Treat is a dummy for municipalities within 10 $\mathrm{km}$ of the border. I control for log of the Swiss GDP, log of the Italian GDP, log of the unemployment rate in Lombardy. Monthly and municipality fixed effects, and a dummy for the period after 2007 are also included. Robust standard errors in parentheses clustered at the municipal level. An observation is a municipality-month-hour. 
Table 9: Monthly average concentration of nitrogen oxides (Nox, mg/m3), Day IV

\begin{tabular}{lcccccc}
\hline & $(1)$ & $(2)$ & $(3)$ & $(4)$ & $(5)$ & $(6)$ \\
& Wday & NWday & Wday & NWday & Wday & NWday \\
& 5am-9am & 5am-9am & 10am-1pm & $10 \mathrm{am}-1 \mathrm{pm}$ & $2 \mathrm{pm}-8 \mathrm{pm}$ & $2 \mathrm{pm}-8 \mathrm{pm}$ \\
\hline Cars & -0.057 & -0.831 & $-1.294^{*}$ & -0.513 & -1.313 & 1.698 \\
\multirow{4}{*}{ Treat*Cars } & $(0.280)$ & $(0.884)$ & $(0.734)$ & $(1.243)$ & $(0.940)$ & $(2.739)$ \\
& $0.904^{* * *}$ & 3.364 & 2.381 & 3.108 & $4.910^{*}$ & -6.433 \\
& $(0.342)$ & $(3.723)$ & $(2.137)$ & $(2.037)$ & $(2.759)$ & $(12.923)$ \\
Observations & 6,383 & 6,328 & 5,113 & 5,068 & 8,938 & 8,861 \\
\hline \hline Mun FE & YES & YES & YES & YES & YES & YES \\
Month FE & YES & YES & YES & YES & YES & YES \\
\hline
\end{tabular}

Note.Years 2005-2014. Data are expressed in parts per million (ppb.). The dependent variable is the monthly average concentration of nitrogen oxides in a given hour. Treat is a dummy for monitoring stations in municipalities within $10 \mathrm{~km}$ of the border. Cars is the log of the average number of cars. I control for log of the Swiss GDP, log of the Italian GDP and log of the unemployment rate in Lombardy. Monthly and station fixed effects, and a dummy for the period after 2007 are also included. Robust standard errors in parentheses clustered at the monitoring station level. An observation is an air monitoring station-month-hour.

Table 10: Monthly probability of an accident, Day, With Minor Personal Injuries,IV

\begin{tabular}{lcccccc}
\hline & $(1)$ & $(2)$ & $(3)$ & $(4)$ & $(5)$ & $(6)$ \\
& Wday & NWday & Wday & NWday & Wday & NWday \\
& 5am-9am & $5 \mathrm{am}-9 \mathrm{am}$ & $10 \mathrm{am}-1 \mathrm{pm}$ & $10 \mathrm{am}-1 \mathrm{pm}$ & $2 \mathrm{pm}-8 \mathrm{pm}$ & $2 \mathrm{pm}-8 \mathrm{pm}$ \\
\hline Cars & 0.058 & -0.054 & -0.058 & -0.165 & -0.050 & 0.127 \\
& $(0.115)$ & $(0.288)$ & $(0.099)$ & $(0.115)$ & $(0.116)$ & $(0.291)$ \\
Treat*Cars & -0.033 & 0.150 & 0.044 & $0.241^{* *}$ & 0.070 & -0.099 \\
& $(0.071)$ & $(0.253)$ & $(0.089)$ & $(0.108)$ & $(0.122)$ & $(0.232)$ \\
& & & & & & \\
Observations & 15,102 & 15,089 & 12,088 & 12,080 & 21,148 & 21,130 \\
\hline Mun FE & YES & YES & YES & YES & YES & YES \\
Month FE & YES & YES & YES & YES & YES & YES \\
\hline
\end{tabular}

Note.Years 2005-2014. The dependent variable is a dummy variable equal to 1 if at least one car accident with minor personal injuries occurs in a given hour. Treat is a dummy for municipalities within $10 \mathrm{~km}$ of the border. Cars is the log of the average number of cars. I control for log of the Swiss GDP, $\log$ of the Italian GDP, log of the unemployment rate in Lombardy. Monthly and municipality fixed effects, and a dummy for the period after 2007 are also included. Robust standard errors in parentheses clustered at the municipal level. An observation is a municipality-month-hour. 
Table 11: Monthly probability of an accident, Day, With Severe Personal Injuries,IV

\begin{tabular}{lcccccc}
\hline & $(1)$ & $(2)$ & $(3)$ & $(4)$ & $(5)$ & $(6)$ \\
& Wday & NWday & Wday & NWday & Wday & NWDAY \\
& 5am-9am & 5 am-9am & $10 \mathrm{am}-1 \mathrm{pm}$ & $10 \mathrm{am}-1 \mathrm{pm}$ & $2 \mathrm{pm}-8 \mathrm{pm}$ & $2 \mathrm{pm}-8 \mathrm{pm}$ \\
\hline Cars & 0.022 & 0.007 & -0.119 & -0.000 & 0.055 & 0.153 \\
& $(0.059)$ & $(0.056)$ & $(0.144)$ & $(0.106)$ & $(0.093)$ & $(0.377)$ \\
Treat*Cars & -0.009 & -0.010 & 0.030 & -0.031 & $-0.134^{*}$ & 0.379 \\
& $(0.044)$ & $(0.051)$ & $(0.097)$ & $(0.073)$ & $(0.081)$ & $(0.504)$ \\
& & & & & & \\
Observations & 15,102 & 15,089 & 12,088 & 12,080 & 21,148 & 21,130 \\
\hline \hline Mun FE & YES & YES & YES & YES & YES & YES \\
Month FE & YES & YES & YES & YES & YES & YES \\
\hline
\end{tabular}

Note.Years 2005-2014. The dependent variable is a dummy variable equal to 1 if at least one car accident with severe personal injuries occurs in a given hour. Treat is a dummy for municipalities within $10 \mathrm{~km}$ of the border. Cars is the log of the average number of cars. I control for log of the Swiss GDP, $\log$ of the Italian GDP, log of the unemployment rate in Lombardy. Monthly and municipality fixed effects, and a dummy for the period after 2007 are also included. Robust standard errors in parentheses clustered at the municipal level. An observation is a municipality-month-hour.

Table 12: Monthly probability of an accident, Day, With Material Damages, IV

\begin{tabular}{lcccccc}
\hline & $(1)$ & $(2)$ & $(3)$ & $(4)$ & $(5)$ & $(6)$ \\
& Wday & NWday & Wday & NWday & Wday & NWDAY \\
& 5am-9am & $5 \mathrm{am}-9 \mathrm{am}$ & $10 \mathrm{am}-1 \mathrm{pm}$ & $10 \mathrm{am}-1 \mathrm{pm}$ & $2 \mathrm{pm}-8 \mathrm{pm}$ & $2 \mathrm{pm}-8 \mathrm{pm}$ \\
\hline Cars & -0.248 & 0.041 & -0.372 & -0.294 & -0.331 & 0.157 \\
& $(0.254)$ & $(0.198)$ & $(0.334)$ & $(0.276)$ & $(0.246)$ & $(0.710)$ \\
Treat*Cars & 0.050 & -0.169 & 0.190 & 0.216 & -0.019 & 0.871 \\
& $(0.223)$ & $(0.226)$ & $(0.338)$ & $(0.281)$ & $(0.275)$ & $(1.090)$ \\
& & & & & & \\
Observations & 15,102 & 15,089 & 12,088 & 12,080 & 21,148 & 21,130 \\
\hline Mun FE & YES & YES & YES & YES & YES & YES \\
Month FE & YES & YES & YES & YES & YES & YES \\
\hline
\end{tabular}

Note.Years 2005-2014. The dependent variable is a dummy variable equal to 1 if at least one car accident with material damages occurs in a given hour. Treat is a dummy for municipalities within $10 \mathrm{~km}$ of the border. Cars is the log of the average number of cars. I control for log of the Swiss GDP, $\log$ of the Italian GDP, $\log$ of the unemployment rate in Lombardy. Monthly and municipality fixed effects, and a dummy for the period after 2007 are also included. Robust standard errors in parentheses clustered at the municipal level. An observation is a municipality-month-hour. 
Appendix 
Table A.1: Monthly average number of cars, Night

\begin{tabular}{|c|c|c|c|c|}
\hline \multicolumn{5}{|c|}{ Panel 1: IT $\rightarrow$ CH, Night } \\
\hline & $(1)$ & $(2)$ & $(3)$ & $(4)$ \\
\hline & Mon-Fri & Sat-Sun & Mon-Fri & Sat-Sun \\
\hline & $8 \mathrm{pm}-11 \mathrm{pm}$ & $8 \mathrm{pm}-11 \mathrm{pm}$ & $12 \mathrm{am}-4 \mathrm{am}$ & $12 \mathrm{am}-4 \mathrm{am}$ \\
\hline \multirow[t]{2}{*}{$\ln \mathrm{e}$} & $-0.234^{* *}$ & $-0.254^{* *}$ & -0.022 & -0.035 \\
\hline & $(0.099)$ & $(0.096)$ & $(0.177)$ & $(0.163)$ \\
\hline \multirow[t]{2}{*}{ Treatment $* \ln \mathrm{e}$} & 0.267 & $0.364^{* *}$ & -0.663 & -0.232 \\
\hline & $(0.167)$ & $(0.162)$ & $(0.560)$ & $(0.539)$ \\
\hline Observations & 9,021 & 9,006 & 14,978 & 14,963 \\
\hline \multirow[t]{5}{*}{ R-squared } & 0.903 & 0.927 & 0.750 & 0.806 \\
\hline & Panel 2: & $\mathrm{CH} \rightarrow \mathrm{IT}, \mathrm{Niq}$ & & \\
\hline & $(1)$ & $(2)$ & $(3)$ & $(4)$ \\
\hline & Mon-Fri & Sat-Sun & Mon-Fri & Sat-Sun \\
\hline & 8pm-11pm & 8pm-11pm & $12 \mathrm{am}-4 \mathrm{am}$ & $12 \mathrm{am}-4 \mathrm{am}$ \\
\hline \multirow[t]{2}{*}{$\ln \mathrm{e}$} & -0.078 & -0.092 & -0.181 & -0.110 \\
\hline & $(0.082)$ & $(0.093)$ & $(0.117)$ & $(0.106)$ \\
\hline \multirow[t]{2}{*}{ Treatment* $\ln$ e } & 0.036 & 0.243 & -0.026 & 0.152 \\
\hline & $(0.110)$ & $(0.144)$ & $(0.652)$ & $(0.665)$ \\
\hline Observations & 9,056 & 9,048 & 15,025 & 15,005 \\
\hline R-squared & 0.903 & 0.941 & 0.794 & 0.823 \\
\hline Controls FE & YES & YES & YES & YES \\
\hline Monthly FE & YES & YES & YES & YES \\
\hline Station FE & YES & YES & YES & YES \\
\hline
\end{tabular}

Notes: The dependent variable is the log of the monthly average number of cars crossing a specific station in a given hour. The symbol ' $\mathrm{CH}->\mathrm{IT}$ ' indicates north-to-south flows, and 'IT- $>$ CH' indicates south-to-north flows. Treatment is a dummy for the traffic-counting stations located within a driving distance of up to $10 \mathrm{~km}$ from the border. Controls include the log of the Swiss GDP, the log of the Italian GDP, and the log of the unemployment rate in Lombardy. Monthly and traffic-counting station fixed effects, as well as a dummy for the period after 2007, are also included. Robust standard errors (in parentheses) are clustered at the traffic-counting station level. An observation is a traffic-counting stationmonth-year-hour. The following symbols indicate different significance levels: ${ }^{* * *} \mathrm{p}<0.01,{ }^{* *} \mathrm{p}<0.05,{ }^{*} \mathrm{p}<0.1$. Source: Sezione Mobilità del Canton Ticino (2005-2015) 
Table A.2: Monthly average concentration of nitrogen oxides (Nox, mg/m3), Night

\begin{tabular}{lcccc}
\hline & $\begin{array}{c}(1) \\
\text { Wday } \\
\text { 9pm-11pm }\end{array}$ & $\begin{array}{c}(2) \\
\text { NWday } \\
\text { 9pm-11pm }\end{array}$ & $\begin{array}{c}(3) \\
\text { Wday } \\
\text { 0am-4am }\end{array}$ & $\begin{array}{c}(4) \\
\text { NWday } \\
12 \mathrm{am}-4 \mathrm{am}\end{array}$ \\
\hline \multirow{2}{l}{$\ln \mathrm{e}$} & 0.030 & -0.167 & -0.206 & -0.237 \\
& $(0.158)$ & $(0.187)$ & $(0.142)$ & $(0.207)$ \\
Treat*ln e & -0.164 & 0.076 & -0.080 & -0.144 \\
& $(0.130)$ & $(0.184)$ & $(0.134)$ & $(0.228)$ \\
Observations & 4,164 & 4,136 & 6,931 & 6,891 \\
R-squared & 0.902 & 0.876 & 0.871 & 0.827 \\
\hline \hline Station FE & YES & YES & YES & YES \\
Monthly FE & YES & YES & YES & YES \\
\hline
\end{tabular}

Note.Years 2005-2015. Data are expressed in ppb (parts per million). The dependent variable is the monthly average concentration of oxides of nitrogen in a given hour. Treat is a dummy for monitoring stations in municipalities within $10 \mathrm{~km}$ of the border. I control for the log of the Swiss GDP, the $\log$ of the Italian GDP and the log of the unemployment rate in Lombardy. Monthly and station fixed effects, and a dummy for the period after 2007 are also included. Robust standard errors in parentheses clustered at the monitoring station level. An observation is an air monitoring station-month-hour. The following symbols indicate different significant levels: ${ }^{* * *} \mathrm{p}<0.01,{ }^{* *} \mathrm{p}<0.05,{ }^{*} \mathrm{p}<0.1$. Source: Sezione Mobilità Canton Ticino

Table A.3: Probability of an accident, With Mild Personal Injuries, Night

\begin{tabular}{lcccc}
\hline & $(1)$ & $(2)$ & $(3)$ & $(4)$ \\
& Wday & NWday & Wday & NWday \\
& 9pm-11pm & 9pm-11pm & 12am-4am & 12am-4am \\
\hline ln e & -0.002 & -0.000 & -0.001 & $0.006^{*}$ \\
& $(0.006)$ & $(0.003)$ & $(0.006)$ & $(0.003)$ \\
Treat*ln e & -0.008 & 0.002 & 0.003 & 0.001 \\
& $(0.006)$ & $(0.004)$ & $(0.007)$ & $(0.003)$ \\
Observations & 53,856 & 53,856 & 89,760 & 89,760 \\
R-squared & 0.035 & 0.022 & 0.027 & 0.016 \\
\hline Municipal FE & YES & YES & YES & YES \\
Monthly FE & YES & YES & YES & YES \\
\hline
\end{tabular}

Note.Years 2005-2014. The dependent variable is a dummy variable equal to 1 if at least one car accident with mild personal injuries occurs. Treat is a dummy for municipalities within $10 \mathrm{~km}$ of the border. I control for the $\log$ of the Swiss GDP, the log of the Italian GDP and the log of the unemployment rate in Lombardy. Monthly and municipality fixed effects, and a dummy for the period after 2007 are also included. Robust standard errors in parentheses clustered at the municipal level. An observation is a municipality-monthhour. The following symbols indicate different significant levels: $* * * \mathrm{p}<0.01$, ${ }^{* *} \mathrm{p}<0.05,{ }^{*} \mathrm{p}<0.1$. Source: Federal Roads Office. 
Table A.4: Probability of an accident, With Severe Personal Injuries, Night

\begin{tabular}{lcccc}
\hline & $(1)$ & $(2)$ & $(3)$ & $(4)$ \\
& Wday & NWday & Wday & NWday \\
& 9pm-11pm & 9pm-11pm & 12am-4am & 12am-4am \\
\hline ln e & -0.002 & 0.003 & 0.000 & 0.001 \\
& $(0.003)$ & $(0.003)$ & $(0.003)$ & $(0.002)$ \\
Treat* ${ }^{*}$ ln e & 0.002 & 0.002 & $0.007^{* *}$ & 0.001 \\
& $(0.004)$ & $(0.003)$ & $(0.003)$ & $(0.001)$ \\
Observations & 53,856 & 53,856 & 89,760 & 89,760 \\
R-squared & 0.019 & 0.004 & 0.011 & 0.009 \\
\hline Municipal FE & YES & YES & YES & YES \\
Monthly FE & YES & YES & YES & YES \\
\hline
\end{tabular}

Note.Years 2005-2014. The dependent variable is a dummy variable equal to 1 if at least one car accident with severe personal injuries occurs. Treat is a dummy for municipalities within $10 \mathrm{~km}$ of the border. I control for the $\log$ of the Swiss GDP, the $\log$ of the Italian GDP and the $\log$ of the unemployment rate in Lombardy. Monthly and municipality fixed effects, and a dummy for the period after 2007 are also included. Robust standard errors in parentheses clustered at the municipal level. An observation is a municipality-month-hour. The following symbols indicate different significant levels: ${ }^{* * *} \mathrm{p}<0.01,{ }^{* *} \mathrm{p}<0.05,{ }^{*} \mathrm{p}<0.1$. Source: Federal Roads Office.

Table A.5: Probability of an accident, With Material Damage, Night

\begin{tabular}{lcccc}
\hline & $(1)$ & $(2)$ & $(3)$ & $(4)$ \\
& Wday & NWday & Wday & NWday \\
& 9pm-11pm & 9pm-11pm & 12am-4am & $12 \mathrm{am}-4 \mathrm{am}$ \\
\hline ln e & $0.032^{* *}$ & 0.004 & -0.007 & -0.005 \\
& $(0.015)$ & $(0.010)$ & $(0.009)$ & $(0.006)$ \\
Treat*ln e & 0.028 & 0.019 & $0.030^{* *}$ & 0.003 \\
& $(0.023)$ & $(0.017)$ & $(0.012)$ & $(0.007)$ \\
Observations & 53,856 & 53,856 & 89,760 & 89,760 \\
\hline Municipal FE & YES & YES & YES & YES \\
Monthly FE & YES & YES & YES & YES \\
\hline
\end{tabular}

Note.Years 2005-2014. The dependent variable is a dummy variable equal to 1 if at least one car accident with material damages occurs. Treat is a dummy for municipalities within $10 \mathrm{~km}$ of the border. I control for the $\log$ of the Swiss GDP, the log of the Italian GDP and the log of the unemployment rate in Lombardy. Monthly and municipality fixed effects, and a dummy for the period after 2007 are also included. Robust standard errors in parentheses clustered at the municipal level. An observation is a municipality-monthhour. The following symbols indicate different significant levels: ${ }^{* * *} \mathrm{p}<0.01$, ${ }^{* *} \mathrm{p}<0.05,{ }^{*} \mathrm{p}<0.1$. Source: Federal Roads Office. 
Table A.6: Monthly average concentration of nitrogen oxides (Nox, mg/m3), Night, IV

\begin{tabular}{lcccc}
\hline & $\begin{array}{c}(1) \\
\text { Wday } \\
\text { 9pm-11pm }\end{array}$ & $\begin{array}{c}(2) \\
\text { NWday } \\
\text { 9pm-11pm }\end{array}$ & $\begin{array}{c}(3) \\
\text { Wday } \\
\text { 0am-4am }\end{array}$ & $\begin{array}{c}(4) \\
\text { NWday } \\
12 \mathrm{am}-4 \mathrm{am}\end{array}$ \\
\hline \multirow{2}{*}{ Cars } & & & & \\
& 0.104 & 0.118 & 0.194 & 0.326 \\
Treat*Cars & $(1.295)$ & $(0.357)$ & $(0.705)$ & $(0.684)$ \\
& -2.944 & -0.620 & -0.966 & -0.911 \\
& $(6.301)$ & $(0.942)$ & $(1.589)$ & $(0.584)$ \\
Observations & 3,828 & 3,789 & 6,352 & 6,297 \\
\hline Station FE & YES & YES & YES & YES \\
Monthly FE & YES & YES & YES & YES \\
\hline
\end{tabular}

Note.Years 2005-2015. Data are expressed in ppb (parts per million). The dependent variable is the monthly average concentration of oxides of nitrogen in a given hour. Treat is a dummy for monitoring stations in municipalities within $10 \mathrm{~km}$ of the border. Car is the $\log$ of the average number of cars. I control for the log of the Swiss GDP, the log of the Italian GDP and the $\log$ of the unemployment rate in Lombardy. Monthly and station fixed effects, and a dummy for the period after 2007 are also included. Robust standard errors in parentheses clustered at the monitoring station level. An observation is an air monitoring station-month-hour. The following symbols indicate different significant levels: ${ }^{* * *} \mathrm{p}<0.01,{ }^{* *} \mathrm{p}<0.05$, ${ }^{*} \mathrm{p}<0.1$. Source: Sezione Mobilità Canton Ticino

Table A.7: Probability of an accident, With Mild Personal Injuries, Night,IV

\begin{tabular}{lcccc}
\hline & $(1)$ & $(2)$ & $(3)$ & $(4)$ \\
& Wday & NWday & Wday & NWday \\
& 9pm-11pm & 9pm-11pm & 12am-4am & 12 am-4am \\
\hline Cars & 0.114 & -0.028 & -0.039 & -0.089 \\
& $(0.138)$ & $(0.087)$ & $(0.184)$ & $(0.190)$ \\
Treat*Cars & -0.197 & 0.018 & 0.062 & 0.010 \\
& $(0.193)$ & $(0.097)$ & $(0.381)$ & $(0.111)$ \\
& & & & \\
Observations & 9,057 & 9,048 & 15,073 & 15,057 \\
\hline Municipal FE & YES & YES & YES & YES \\
Monthly FE & YES & YES & YES & YES \\
\hline
\end{tabular}

Note. Years 2005-2014. The dependent variable is a dummy variable equal to 1 if at least one car accident with mild personal injuries occurs. Treat is a dummy for municipalities within $10 \mathrm{~km}$ of the border. Car is the log of the average number of cars. I control for the log of the Swiss GDP, the log of the Italian GDP and the log of the unemployment rate in Lombardy. Monthly and municipality fixed effects, and a dummy for the period after 2007 are also included. Robust standard errors in parentheses clustered at the municipal level. An observation is a municipality-month-hour. The following symbols indicate different significant levels: ${ }^{* * *} \mathrm{p}<0.01,{ }^{*} \mathrm{p}<0.05,{ }^{*} \mathrm{p}<0.1$. Source: Federal Roads Office. 
Table A.8: Probability of an accident, With Severe Personal Injuries, Night,IV

\begin{tabular}{lcccc}
\hline & $(1)$ & $(2)$ & $(3)$ & $(4)$ \\
& Wday & NWday & Wday & NWday \\
9pm-11pm & 9pm-11pm & 12am-4am & $12 \mathrm{am}-4 \mathrm{am}$ \\
\hline Cars & -0.023 & -0.103 & -0.114 & 0.043 \\
Treat*Cars & $(0.095)$ & $(0.124)$ & $(0.383)$ & $(0.081)$ \\
& 0.124 & 0.126 & 0.191 & -0.006 \\
& $(0.170)$ & $(0.077)$ & $(0.778)$ & $(0.050)$ \\
Observations & 9,057 & 9,048 & 15,073 & 15,057 \\
\hline Municipal FE & YES & YES & YES & YES \\
Monthly FE & YES & YES & YES & YES \\
\hline
\end{tabular}

Note.Years 2005-2014. The dependent variable is a dummy variable equal to 1 if at least one car accident with severe personal injuries occurs. Treat is a dummy for municipalities within $10 \mathrm{~km}$ of the border. Car is the log of the average number of cars. I control for the log of the Swiss GDP, the log of the Italian GDP and the log of the unemployment rate in Lombardy. Monthly and municipality fixed effects, and a dummy for the period after 2007 are also included. Robust standard errors in parentheses clustered at the municipal level. An observation is a municipality-month-hour. The following symbols indicate different significant levels: ${ }^{* * *} \mathrm{p}<0.01,{ }^{* *} \mathrm{p}<0.05,{ }^{*} \mathrm{p}<0.1$. Source: Federal Roads Office.

Table A.9: Probability of an accident, With Material Damage, Night, IV

\begin{tabular}{lcccc}
\hline & $(1)$ & $(2)$ & $(3)$ & $(4)$ \\
& Wday & NWday & Wday & NWday \\
9pm-11pm & 9pm-11pm & 12am-4am & 12am-4am \\
\hline Cars & -0.586 & -0.225 & -0.976 & 0.036 \\
Treat*Cars & $(0.557)$ & $(0.318)$ & $(5.244)$ & $(0.143)$ \\
& 1.247 & 0.395 & 2.166 & -0.032 \\
& $(1.433)$ & $(0.398)$ & $(9.624)$ & $(0.058)$ \\
Observations & 9,057 & 9,048 & 15,073 & 15,057 \\
\hline Municipal FE & YES & YES & YES & YES \\
Monthly FE & YES & YES & YES & YES \\
\hline
\end{tabular}

Note.Years 2005-2014. The dependent variable is a dummy variable equal to 1 if at least one car accident with material damages occurs. Treat is a dummy for municipalities within $10 \mathrm{~km}$ of the border. Car is the log of the average number of cars. I control for the log of the Swiss GDP, the log of the Italian GDP and the log of the unemployment rate in Lombardy. Monthly and municipality fixed effects, and a dummy for the period after 2007 are also included. Robust standard errors in parentheses clustered at the municipal level. An observation is a municipality-month-hour. The following symbols indicate different significant levels: ${ }^{* * *} \mathrm{p}<0.01,{ }^{* *} \mathrm{p}<0.05,{ }^{*} \mathrm{p}<0.1$. Source: Federal Roads Office. 


\section{IdEP Economic Papers}

The series IdEP Economic Papers, ideally continues the work of the "Quaderni della Facoltà" the publication of which began in 1998 and ended in 2013.

For a complete list of the Quaderni see: http://econpapers.repec.org/paper/lugwpaper/

IdEP Economic Papers also gathers the legacy of the CEPRA Working Papers, published from 2012 to 2013

The full list at: http://econpapers.repec.org/paper/lugwcepra/

2014:

No. 01

F. Mazzonna, F. Peracchi, Unhealthy retirement? Evidence of occupation heterogeneity

No. 02

L. Di Giorgio, M. Filippini, G. Masiero, The relationship between costs and quality in nonprofit nursing homes

No. 03

F.C. Billari, V. Galasso, Fertility decisions and pension reforms : evidence from natural experiments in Italy

No. 04

M. Jametti, M. Joanis, Elections and de facto expenditure decentralization in Canada

No. 05

M. Jametti, Weathering the global financial crisis : is direct democracy of any help?

No. 06

U. Pagano, M. Vatiero, Costly institutions as substitutes : novelty and limits of the Coasian approach

No. 07

R. Parchet, Are local tax rates strategic complements or strategic substitutes?

No. 08

R. Ippoliti, M. Vatiero, An analysis of how 2002 judicial reorganization has impacted on the performance of the First Instance Courts (Preture) in Ticino

No. 09

F. Mazzonna, P. Salari, Short term effects of public smoking bans on health 
2015:

No. 01

S. Galletta, Direct democracy, partial decentralization and voter information : evidence from Swiss municipalities

No. 02

I. Sarman, Second homeowners' intention to move : an integrated ordered logit model with latent variable

No. 03

M.J. Roe, M. Vatiero, Corporate governance and its political economy

No. 04

M. Filippini, M. Koller, G. Masiero, Competitive tendering versus performance-based negotiation in Swiss public transport

No. 05

O. Giuntella, F. Mazzonna, If you don't snooze you lose health and gain weight : evidence from a regression discontinuity design

No. 06

M. Filippini, B. Hirl, G. Masiero, Rational habits in residential electricity demand

2016:

No. 01

S. Galletta, Law enforcement, municipal budgets and spillover effects : evidence from a quasiexperiment in Italy

No. 02

S. Galletta, A. Redonda, Corporate flat tax reforms and businesses'location choices. Evidence from Switzerland

No. 03

M. Filippini, W. Greene, G. Masiero, Persistent and transient productive inefficiency in a regulated industry: electricity distribution in New Zealand 
No. 04

M. Vatiero, On the (political) origin of "corporate governance" species

No. 05

E. Gentili, G. Masiero, F. Mazzonna, The role of culture in long-term care

No. 06

M. Vatiero, Learning from the Swiss corporate governance exception

No. 07

F. Cavalcanti, G. Daniele, S. Galletta, Popularity shocks and political selection : the effects of anti-corruption audits on candidates' quality

2017:

No. 01

P. Bello, Exchange rate fluctuations and border crossings : evidence from the Swiss-Italian border

No. 02

E. Gentili, F. Mazzonna, What drives the substitutability between native and foreign workers? Evidence about the role of language

No. 03

G. Daniele, S. Galletta, B. Geys, Abandon ship? Party brands and politicians' responses to a political scandal

2018:

No. 01

G. Masiero, F. Mazzonna, O. Verbeek, What drives the rise of antidepressant consumption? Evidence from Switzerland

No. 02

U. Pagano, M. Vatiero, Positional goods and legal orderings 
2019:

No. 01

G. Masiero, M. Santarossa, Earthquakes, grants and public expenditure : how municipalities respond to natural disasters

No. 02

G. Masiero, F. Mazzonna, S. Steinbach, O. Verbeek, The effect of local growth in antidepressant consumption on mental health outcomes

No. 03

T. Ly, Taxes, traffic jam and spillover in the metropolis

2020:

No. 01

P. Bello, The environmental cost and the accident externality of driving: evidence from the Swiss franc's appreciation 